\title{
Integrated computational product and production engineering for multi-material lightweight structures
}

\author{
André Hürkamp ${ }^{1}$. Antal Dér ${ }^{1} \cdot$ Sebastian Gellrich ${ }^{1} \cdot$ Tim Ossowski ${ }^{1} \cdot$ Ralf Lorenz $^{2} \cdot$ Bernd-Arno Behrens $^{2}$. \\ Christoph Herrmann ${ }^{1}$. Klaus Dröder ${ }^{1}$. Sebastian Thiede ${ }^{1}$
}

Received: 12 March 2020 / Accepted: 9 August 2020 / Published online: 11 September 2020

(C) The Author(s) 2020

\begin{abstract}
Within product development processes, computational models are used with increasing frequency. However, the use of those methods is often restricted to the area of focus, where product design, manufacturing process, and process chain simulations are regarded independently. In the use case of multi-material lightweight structures, the desired products have to meet several requirements regarding structural performance, weight, costs, and environment. Hence, manufacturing-related effects on the product as well as on costs and environment have to be considered in very early phases of the product development process in order to provide a computational concept that supports concurrent engineering. In this contribution, we present an integrated computational concept that includes product engineering and production engineering. In a multi-scale framework, it combines detailed finite element analyses of products and their related production process with process chain and factory simulations. Including surrogate models based on machine learning, a fast evaluation of production impacts and requirements can be realized. The proposed integrated computational product and production engineering concept is demonstrated in a use case study on the manufacturing of a multi-material structure. Within this study, a sheet metal forming process in combination with an injection molding process of short fiber reinforced plastics is investigated. Different sets of process parameters are evaluated virtually in terms of resulting structural properties, cycle times, and environmental impacts.
\end{abstract}

Keywords Product development $\cdot$ Production engineering $\cdot$ Multi-scale simulation $\cdot$ Machine learning $\cdot$ Multi-material lightweight structures

\section{Introduction}

In today's product development, virtual tools are used more frequently, leading to a reduction of physical prototypes and experimental testing. Virtual testing leads to a reduction of the development time, to cost savings, and to an increase in quality due to the fast evaluation of different designs [1]. A development without physical prototypes can therefore contribute to an improvement in the economic and environmental efficiency of product development processes. Especially potential environmental impacts can hardly be

André Hürkamp

a.huerkamp@tu-braunschweig.de

1 Institute of Machine Tools and Production Technology, Technische Universität Braunschweig, Langer Kamp 19b, 38106 Braunschweig, Germany

2 Institute of Forming Technology and Machines, Leibniz Universität Hannover, An der Universität 2, 30823 Garbsen, Germany tested by physical prototypes. Virtual methods, which make it possible to determine the environmental impacts over the life cycle of a product, can therefore significantly support product development with regard to environmental impact reduction [2]. However, a progressive reduction of prototypes and experiments is a major challenge, as this directly depends on the quality and efficiency of virtual models and methods.

Within the product development process, the product engineering focuses on product-related properties. In addition, knowledge of the manufacturing process is necessary since product design and product properties influence the manufacturing and vice versa. In order to shorten development times, an integrated product development including design engineering, production engineering, and other disciplines is used. Such an iterative development method is referred to as concurrent engineering. In this contribution, we focus on the interaction between product engineering and production engineering employing integrated virtual prototypes. 
Nowadays, digital and virtual representations of the geometry by computer-aided design (CAD) and numerical methods, such as the finite element method (FEM), are commonly used in the field of computer-aided engineering (CAE). Throughout the entire product development process, numerous virtual representations exist. Typically, for each development phase, the geometry is taken from a central CAD file. Hence, each simulation model is then a individually modified model with a certain level of abstraction to evaluate physical properties, such as the structural performance of a product, or to evaluate manufacturing aspects (e.g., tool design, process setup, and assembly of components). For an efficient product development, the computational models used for product engineering as well as for the production engineering have to be combined.

In this case, it is not sufficient to share only geometric information. It rather requires an intensive exchange of information between manufacturing simulation and structural analysis. Multi-scale simulations are suitable approaches to capture effects at different scales of the product as well as of the production. In the context of production systems, the Integrated Computational Materials Engineering (ICME) focuses on the microstructure of materials and the effects of processing [3]. In ICME, methods from computational materials science and multi-scale mechanics are used to support materials design [4]. Despite the consideration of the manufacturing process, ICME focuses mainly the material rather than the production (system). A wider range is represented within the Integrated Computational Materials and Production Engineering [5] combining materials and machining simulation with factory and production planning. The necessity of implementing multi-scale simulation tools in hierarchical plant models is also pointed out in [6].

The idea of an integrated computational engineering approach becomes even more important; when in contrast to conventional production processes for mono-material structures, multi-material lightweight structures (MMLS) are achieved by multi-stage and integrated manufacturing. They are physical products or parts of products that consist of different materials with different properties (e.g., steel and fiber-reinforced plastics) and enable a required technical functionality at a lower weight than generally achievable by other means [7]. The resulting mechanical properties are then significantly influenced by the manufacturing process [8]. Hence, the requirements for the virtual modeling along the product development process of MMLS are increased. Furthermore, with increasing number and complexity of manufacturing processes and the use of several dissimilar materials, a continuously available virtual process chain becomes mandatory [9].
Despite the lightweight potential of MMLS, their manufacturing and integration into existing production systems remain challenging. For example, the use of fiber-reinforced materials leads to higher material costs and environmental burdens compared with conventional steel structures. However, due to the integration of joining processes in the manufacturing, the number of subsequent processes decreases, which is beneficial in terms of costs regarding the total process chain. When processing thermoplastic materials, MMLS tend to have more energy intensive production steps compared to conventional steel structures. Consequently, integrated production processes for MMLS cause a higher complexity compared with conventional steel processing. This also raises the question of their environmental competitiveness, which has to be assessed in the context of their entire life cycle and can only be investigated by virtual prototypes.

To address the resulting challenges, we propose a concept for an integrated computational product and production engineering (ICPPE). In this context, product denotes a physical product or part of a product. The outlined concept is generally applicable and shows an integrated multi-scale scheme in order to connect different engineering disciplines along the product development more closely. ICPPE allows considering product and production impacts and requirements already in early development stages. Moreover, it enables the estimation of manufacturing times and costs as well as the environmental impact. In addition, that information allows a scenario assessment for the life cycle engineering to identify compromises and potential improvements in very early development phases. Beyond the engineering specific tasks, also superordinate factory planning processes benefit from ICPPE due to the modelbased understanding of processes inside and across process chains.

In order to illustrate the proposed concept, the paper is structured as follows. After a short review of current state of the art methods used in computational engineering and in the field of process chain modeling (Section 2), the overall concept of ICPPE is presented in Section 3 (cf. Fig. 2) and the individual levels are described in detail. The presented concept is demonstrated in Section 4 on a use case example of a MMLS consisting of a metal component and a fiber-reinforced plastic (FRP) component (cf. Fig. 7). Conclusion and outlook are given in Section 5 .

\section{Computational methods in product and production engineering}

Different computational simulation methods are used during the product development process. Regarding the entire 


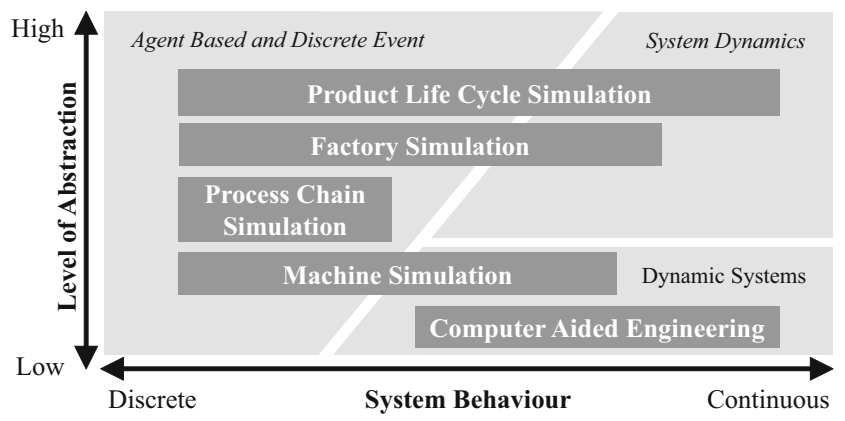

Fig. 1 Structure of simulation models for different production system elements; inspired by $[13,14]$

production system, for example, we find that different spatial and temporal scales are involved [10-12]. The modeling and simulation methods used at each of these scales require a certain level of detail. Figure 1 depicts a classification of simulation methods for different production system elements with respect to the level of abstraction and the system behavior.

The virtual representation of physical systems consists of mathematical variables. To investigate the system behavior virtually, computer algorithms are used to manipulate these variables in accordance with the given set of parameters, and mathematical and physical models used.

The physically detailed simulations analyzing product properties due to the production process are based on principles of computational mechanics, which is generally referred to as computer-aided engineering. This class belongs to the field of dynamic systems, where commonly finite element analyses (FEA) are carried out to estimate the material behavior.

In modeling virtual manufacturing process chains, the discrete event simulation paradigm has prevailed. Discrete event simulations are applied to model and understand the dynamic interdependence between process steps and to detect time bottlenecks [15]. Agent-based simulation and hybrid modeling approaches combining multiple simulation paradigms within one model (cf. Fig. 1) have been applied in academia to predict the energy demand of production systems on different levels such as process, process chain, and factory level $[14,16,17]$.

\subsection{Computer-aided engineering}

In the field of computational mechanics, numerical methods such as FEM are commonly used for solving problems in engineering and mathematical physics. Basic differential equations are the balance of linear momentum, the first law of thermodynamics, and in the case of fluid problems the Navier-Stokes equations [18, 19]. Numerical solutions of those basic equations are available in numerous commercial software systems. In this work, we focus on the numerical analysis of the manufacturing processes deep drawing and injection molding.

\subsubsection{Sheet metal forming}

Nowadays, three-dimensional computations of deep drawing processes under consideration of a planar anisotropy have become a matter of course. With the help of additional adaptive mesh refinement algorithms, even complex sheet metal components can be efficiently simulated within acceptable computing times [20]. In early 2000s, the state of the art of process variables that can be calculated reliably using FEM were successively extended [21-23]. This includes failure due to fracture, sheet thickness, strain distribution, wrinkling, blank-holder force, and strain-based damage. Therefore, it is possible to achieve improved tool designs and process times, as well as a high product quality. For determining the stress distribution in deep-drawn parts, the calculation of the elastic-plastic part of the forming process is necessary, since even small deviations of plastic deformations have a considerable influence on the springback $[24,25]$. Springback and stress-based damage are still challenging issues in deep drawing simulations. Also, failures due to friction are difficult to predict. In this respect, existing friction models are constantly being advanced and improved [26]. With the growing demand for new materials like fiber-reinforced thermoplastics as well as their functional combination to metals, temperature effects due to forming at elevated temperatures have become an important factor as well [27].

\subsubsection{Injection molding}

Injection molding of thermoplastics is a highly efficient manufacturing process and therefore commonly used for plastic parts in large-scale production industries. The numerical analysis of the injection molding process is used for improving tooling and product quality [28, 29]. Process parameters can be identified finding optimal process settings for mold filling. Furthermore, cooling [30, 31] and runner systems [32,33] can be optimized. In addition to the process and tool design, effects influencing the structural performance can also be analyzed. Those effects are e.g. the position of weld lines [34] or, in the case of FRP, the fiber orientation due to the plastic flow [35-37]. In this work, we focus on short fiber-reinforced thermoplastics (SFRTP), where the obtained fiber orientation mainly influences the thermoelastic properties [38] and the failure [39]. For the structural analysis, the fiber orientation is mapped onto the structural mesh to consider the process-induced anisotropy [40, 41]. Furthermore, residual stresses due to the manufacturing process are considered in subsequent analyses for computing distortions of the structure [42, 43]. 


\subsection{Model order reduction and surrogate modeling}

The simulations in the field of CAE are usually computationally expensive. In order to speed up the computing time, methods from model order reduction (MOR) and machine learning can be exploited to reach real-time applications. Based on those techniques, surrogate models are derived from a parametric solution that contains (all) possible scenarios [44]. MOR techniques approximate the solution of a physical system without simplifying the model and the underlying physics. MOR is closely related to the field of surrogate modeling. The dimension reduction by Principal Component Analysis (PCA) of data builds the first step [45]. Based on PCA, the proper orthogonal decomposition (POD) [46] can be used for a projection-based model reduction, where the projection vectors are determined from precomputed parametric solutions. In the context of robot-based incremental sheet metal forming, Rademacher et al. [47] have applied a selective POD to reduce the computational effort. It is also suitable for the analysis of material nonlinearities and large deformations [48, 49]. An extension of POD is the Proper Generalized Decomposition (PGD) [5052], where the reduced basis functions are computed on the fly. According to [44], such numerical models are referred to as virtual twins. Furthermore, PGD-based virtual twins can be used in combination with online process data for a cyber physical system approach in order to allow predictive maintenance [53].

Surrogate modeling, according to [54], is a "technique that makes use of the sampled data to build surrogate models, which are sufficient to predict the output of an expensive computer code at untried points in the design space". In the context of process simulation, the sampled data are derived by a FEM parameter study (details on this approach can be found in Sections 3.3 and 4.3). The surrogate models enable a fast and accurate search throughout the parameter space, e.g., quickly delivering sweet spots for the part design and the production engineering. Surrogates can further be used to bridge the gap between the high level of detail needed for dynamic systems in CAE to more abstraction at process chains or factory simulations.

The general procedure for building surrogate models from FEA covers the following consecutive phases: definition of design space and sample points via a design of experiment (DoE), a sufficient amount of FEM runs for the derivation of a sampled data base on which the surrogate models are trained (e.g., through machine learning approaches), and finally evaluation of the trained surrogate models [54]. For covering the surrogate learning task, some approaches have been demonstrated in literature that all rely on machine learning concepts-polynomial response surface model (RSM), kriging algorithm, radial basis functions (RBFs) [54], artificial neural network (ANN) [55, 56], multiple adaptive regression splines (MARS), as well as support vector regression (SVR) [57].

A demonstration of machine learning-based surrogate modeling of FEM is shown by [58] in the medical technology context of estimating wall stress distribution of an 3D aorta shape. The deep learning approach comprises three steps: (I) shape decoding of input shape, (II) nonlinear mapping of input shape code to output stress code, and (III) stress decoding to wall stress distributions. For shape decoding, PCA is applied. Machine learning approaches are deployed for nonlinear mapping and stress decoding in terms of multilayer neural network and convolutional neural network approaches.

\subsection{Process chain modeling using discrete event and agent-based simulation}

Traditional process chain modeling and simulation has been applied by practitioners in academia and industry for general system design and manufacturing system operation [59]. Dimensioning the capacity of machines and buffers, detecting bottlenecks, and reducing costs are typical objectives of traditional process chain simulation approaches [59]. Over the past years, modeling and simulation have been accepted as a suitable approach for investigating also the energy demands of manufacturing systems on different system levels [60, 61]. In this context, agent-based modeling approaches have seen an emerging application [62]. Energy-oriented simulation approaches of production systems address different elements of factory systems, ranging from process and machine [63] over to process chains with or without technical building services (TBS) [64] and holistic multi-scale production system simulations including all levels of a production system [14, 65]. In the context of lightweight structures, Schönemann et al. [66] introduce a multi-scale modeling and simulation approach that combines multiple models on different scales (e.g., product, process, process chain, and factory building) to simulate the accurate energy demand of manufactured products.

\section{Concept for an integrated computational product and production engineering}

The proposed concept of ICPPE is depicted in Fig. 2. It combines product engineering and production engineering within an integrated computational concept. During the product development, different tasks have to be solved that require specific levels of abstraction. Hence, different models and methods are needed in each phase according to the regarded system (cf. Fig. 1) and the relevant 


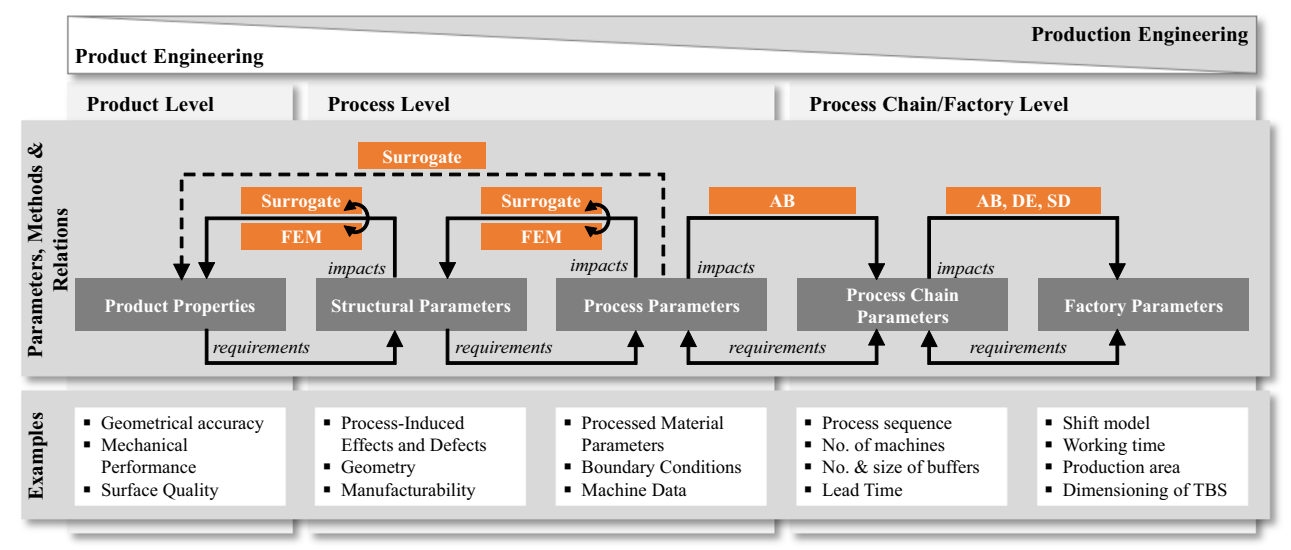

Fig. 2 Concept of the Integrated Computational Product and Production Engineering (ICPPE)

tasks. Within the integration of product engineering and production engineering, the three levels Product Level, Process Level, and Process Chain/Factory Level are distinguished. At each level, different simulation methods are utilized with respect to the desired level of detail. At the beginning of the product development, certain specifications concerning the product properties such as the mechanical performance (e.g., strength, stiffness) are defined. The mechanical properties are mainly influenced by structural parameters, such as fiber orientation in composite materials or thickness distribution for sheet metal structures. In order to estimate the mechanical response due to the structural properties, finite elements are well established. However, the desired product properties give requirements for the structural parameters. To take up the example of composites, the fiber orientation is mainly influenced by the manufacturing process. Hence, the process parameters have a significant impact on the structural parameters and consequently on the product properties. The relation between process and structural parameters can be investigated numerically by FEM. In computer-aided engineering, this leads to a virtual process chain, where the simulation of the manufacturing process is coupled with the stress analysis of the virtual product. Since detailed FEA on product and process level are time consuming, surrogate models can be exploited in order to allow fast optimization tasks. In the present concept, those surrogate models use data analysis techniques to obtain surrogate models from FEM data.

Besides physical properties, also cycle times, temperatures, and machine forces can be estimated already from FEA. This information is necessary for the production engineering in order to provide machine availability and corresponding process chains to meet the lead time. A single process step is embedded into a process chain. Thus, process and process chain parameters directly influence each other. In addition with machine data and information on the process sequences, the FEA data obtained on the process level are used as input for the process chain simulation.
On the process chain/factory level, the detailed physics of the process level are less important and therefore mainly agent-based and discrete event simulations are exploited. Furthermore, the process chains set requirements for the factory in terms of TBS and vice versa.

The present concept allows to investigate effects at each level during the product development to deduce requirements for the factory depending on the desired product properties. Also, it is possible to determine if an existing TBS is sufficient to produce new developed products with existing installations. This fact becomes even more important when new materials or manufacturing processes are to be introduced into existing production lines. Hence, within this concept, an integrated scheme is available to speed up the development times from the first design phase to the start of production. In the following, a detailed description of the three levels is given in terms of input, output, and the used methods.

\subsection{Product level}

In general, the product development starts with the idea and first design sketches. Under consideration of several restrictions concerning process and design space, usually computational-aided design (CAD) tools (potentially in combination with topology optimization) are used for the first product design [67].

Afterwards, an iterative process starts, where methods of computational engineering are employed to evaluate product properties such as stiffness, static, dynamic and fatigue strength. Different designs and material combinations are tested virtually to optimize the desired product. Using e.g. FEM, those simulations yield detailed information about the physical behavior of the product and the mechanical product requirements can be assured. However, for many applications, these simulations cannot be regarded without information of the production at the process level. In the context of ICPPE, residual stresses, distortion, and the fiber orientation of FRP have to be 
mapped onto the product level instead of using ideal CAD geometries and material orientations. Especially, for composite materials and MMLS, the manufacturing process has a main influence on the product properties.

In Fig. 3, the methodology is shown exemplary. The input for the simulation is given by the results of the process level either from detailed FEA results or in the form of surrogate models. These input data contain the geometry after manufacturing and effects induced by the process. Together with the corresponding material parameters, a structural analysis by FEM is utilized. As an direct output, reaction forces, stresses, and other field variables can be evaluated to estimate the product properties.

\subsection{Process level}

The process level represents a single manufacturing process. A challenge in current engineering practice is the lack of knowledge of the manufacturing process in early stages of product development. Hence, the product engineer may not have all relevant information (e.g., fiber orientation, weld lines, or springback) needed for the FEA. Due to the lack of time, it is often not practicable to carry out a manufacturing analysis as an input for the structural analysis. The more complex material and geometry are, the more detailed the simulation model has to be set up and field variables have to be mapped between different finite element meshes. However, process simulations are necessary for a computational production engineering to investigate process and tool designs as well as the influence on structural parameters.

On the process level, the influence of the process on the product properties is investigated numerically. Typical input parameters are the material data of the processed materials, process and machine parameters, and geometric information in terms of effective surfaces and cavities. In order to analyze the process in detail, numerical methods

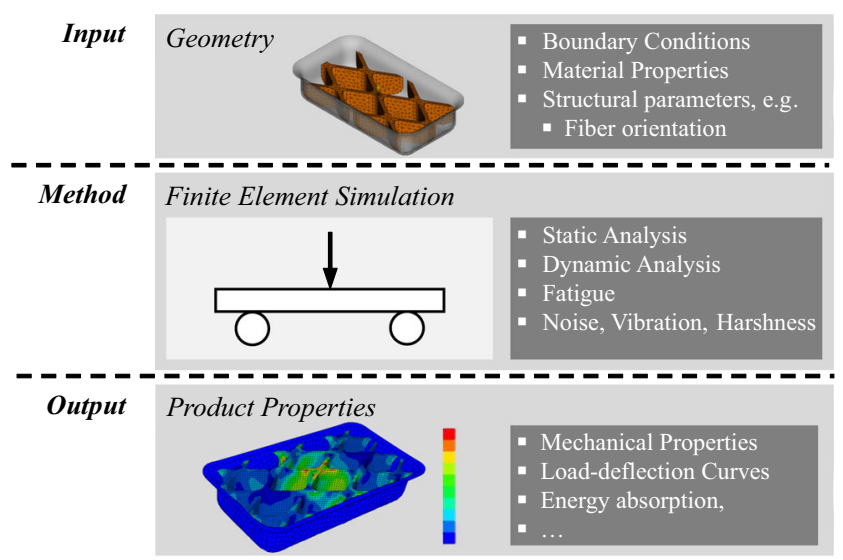

Fig. 3 Methodology for virtual prototyping on the product level such as FEM are used. The output of the process simulation is the final geometry with its process-induced effects and defects. The procedure on the process level is summarized in Fig. 4.

In addition, parametric studies allow computing manufacturing process output for different sets of process parameters. The obtained FEA data can be used to develop surrogate models that overcome large computation times. Such models provide a fast yet accurate tool to estimate directly the output in dependence of the input parameters. Having a suitable surrogate model at hand, it can be used at different phases during the product development for fast and accurate assessments of parameter variations or as a direct input in the simulation on the product level (cf. Fig. 3).

Furthermore, demands for tooling and machines can be estimated. Parametric studies at the process level serve as input for process chain and factory simulation. Here, machine-related requirements can be evaluated to estimate e.g. the demand for energy and to optimize the material flow within the factory.

\subsection{Surrogate modeling}

Surrogate models strive to describe the underlying phenomena in an appropriate manner, which enables a fast and accurate search across the parameter space. Especially, the manufacturing discipline of engineering design, e.g., CFD or FEM, deploys computational expensive codes, consuming days or weeks for a parameter study. However, an adequate FEA result within a few seconds is crucial for a precise estimation of the process settings influences single production processes on the part properties, e.g., structural properties like the fiber orientation in fiber injection molding. Solving a classical FEM problem is unsuitable for this due to its high computing time. A possible approximation, especially for not computed process parameter combinations, can be realized via a lookup table with interpolation

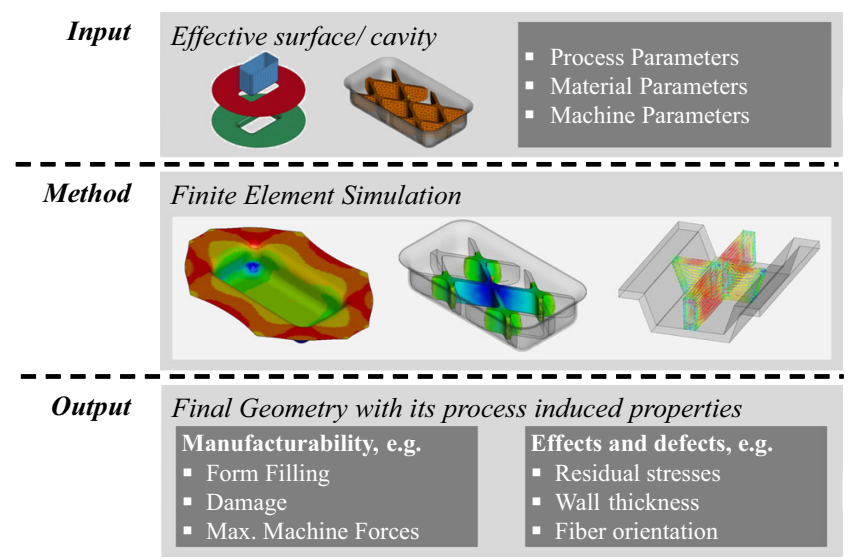

Fig. 4 Methodology for virtual manufacturing on the process level 
between parameters. However, for a fast, precise, and nonlinear approximation, a method based on supervised machine learning is presented for surrogate modeling of a FEM parameter study. The FEM surrogate model can then be used for adequate simulation parametrization on process chain and factory level.

In FEM surrogate modeling, machine learning concepts are deployed on FEM parameter studies to facilitate a rapid estimation of part properties. Figure 5 depicts the general modeling procedure, exemplified by a tensile test specimen manufactured through injection molding.

The procedure is adapted from [58], who proposed a deep learning approach for the estimation of stress distribution of an aorta and is separated into three consecutive parts-input for modeling, nonlinear modeling, and modeling output, i.e., the FEM surrogate model. The surrogate model does not necessarily capture only a single part property, i.e., single output regression, but can comprise multiple properties, i.e., multi output regression, like the fiber orientation and final geometry of the tensile test specimen (see Fig. 5). The non-linear modeling, i.e., multi output regression, connects the input data with the part properties by assigning each input sample a set of target variables, i.e., part properties. Because of the labeled data set, FEM surrogate modeling is a supervised learning task. Furthermore, the part properties have a numeric scale of measure, making it a regression task. Machine learning methods that meet these characteristics are, for example, regression trees and multilayer neural networks for regression.

In order to find a well-fitting surrogate model, the nonlinear modeling step comprises a model parameter refinement for each deployed method as well as a model benchmark. Due to the multi-output modeling approach, an ensemble of regression methods, e.g., each model being responsible for a specific part property, may be the best fit, forming the final FEM surrogate model. As model input, i.e., independent variables, the FEM mesh of the

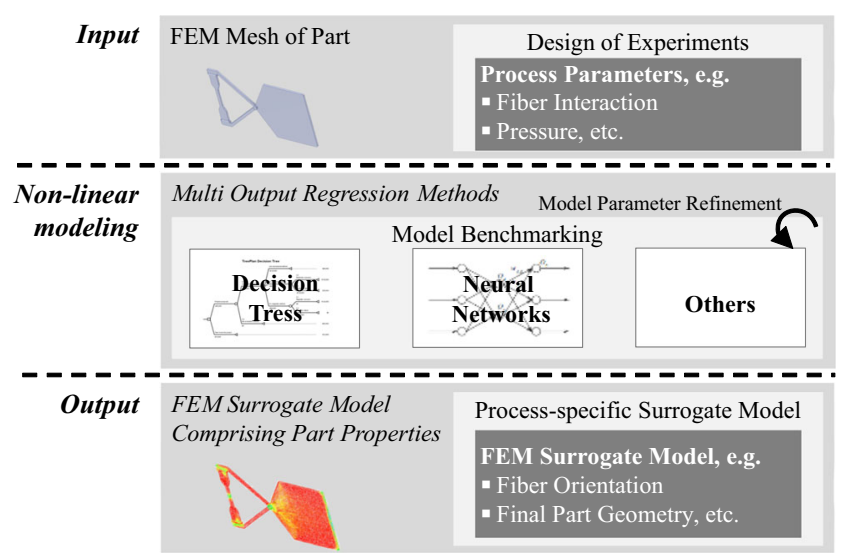

Fig. 5 Nonlinear modeling procedure for FEM surrogate modeling part as well as a sufficient DoE of process setting values is used. Depending on the part, the FEM mesh consists of several thousand nodes each representing a sample data point that the output is mapped on. Each sample comprises the $x, y$, and $z$ coordinates of the node, i.e., features of the model. These features are supplemented by the setting values of the DoE, e.g., a fiber interaction value. If complex parts or extensive DoEs are investigated, a model reduction approach prior to non-linear modeling may be vital, in order to reduce the computational effort. Subsequent to non-linear modeling, a mapping to the original parameter space could be performed.

\subsection{Process chain and factory level}

The modeling approach on the process chain level, shown in Fig. 6, integrates energy-oriented bottom-up machine models in a generic process chain model. Modeling and simulation on process chain and factory level provide valuable inputs for the design of the process chain and a successive life cycle evaluation.

The bottom-up machine models provide state-based energy demands of main machine components, such as drives, tempering units, and hydraulic components. The machine models permit an energy assessment of the production process as a function of process parameters coming from numeric process simulation or surrogate models. The modeling of different machines follows the same generic states, as recommended by [65]: off, ramp-up, standby, and processing. The processing state is machine specific and includes further sub-states to model the process sequence accurately. Parametrization of the machine models is facilitated with product, process, and machine parameters.

Product parameters include characteristics that influence the direct energy demand for processing such as mass, specific heat capacity, and geometry. Furthermore, product

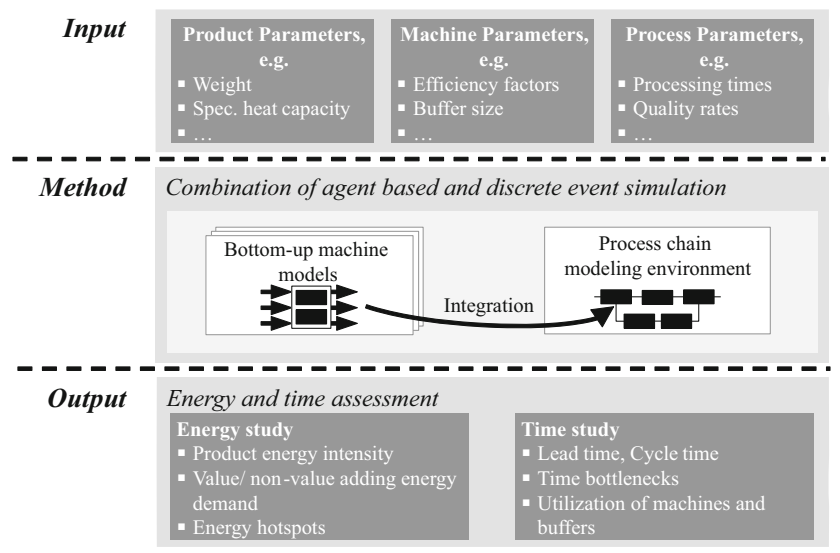

Fig. 6 Integration of energy-oriented machine models into a generic process chain modeling environment 
characteristics that describe the mechanical performance of the product such as ductility, strength, or fiber orientation are not further relevant for the process chain modeling approach. Process parameters describe the execution of the process. Typical parameters in the field of MMLS are processing times, temperatures, and pressures. Machine parameters cover the dimensioning and efficiency of machine components, such as nominal power or flow rates and efficiency factors at different operating points. Product and process parameters are imported from the numeric process simulation or surrogate models. Machine parameters are either based on existing machines or on empirical values based on expert knowledge. Process and machine parameters provide the basis for calculating the energy demand for the machine components. The calculations follow a backward logic: firstly defining the energy required for the production process itself and secondly calculating each component's power demand considering the efficiency of machine components.

The generic process chain model represents a modeling environment for flexibly setting up process chains and embedding them in a factory environment. Connecting several machine models to a process chain allows for further analyses beyond solely energy demands. Isolated machine models do calculate the direct energy demand of one product. They neglect however indirect energy demands for waiting times and machine ramp-ups. The model logic distinguishes between the direct energy demand $E D_{\text {direct }}$ and the indirect energy demand $E D_{\text {indirect }}$. Both direct and indirect energy demands are summed up over all process steps to form the product's energy intensity. The distinction between direct and indirect energy demands builds up on the definitions provided by $[61,68]$. In this modeling approach, the direct energy demand arises from the processing stage of the machine while the energy demand from all other stages accounts for the indirect energy demand. Individual process times on machine level lead to an uneven utilization of machines and bottlenecks in the process chain. This again leads to indirect energy demands occurring in waiting times, which have to be allocated on the produced parts. The process chain perspective also allows for assessing the impacts of quality rates and the placement of quality gates in the process chain on the material and energy efficiency. As an example, a lower quality rate decreases the material efficiency, increases the indirect energy demand of good parts, and affects the utilization of upstream machines as well. In addition to quality rates, the machine models also consider the material efficiency of the processes. This allows for evaluating the required total input material for producing a final product.

\section{Case study on a multi-material lightweight structure}

In this section, we demonstrate the potential of the proposed computational concept on a generic MMLS. In the concept of multi-material design, different classes of materials are combined within one or more manufacturing steps. This enables a highly efficient use of material and an optimized structural design [69]. In automotive applications, the combination of sheet metals with fiber reinforced thermoplastics (FRTP) leads to significant weight reduction and an improvement of the crash behavior [70]. Compared with solely composite solutions, hybrid FRTP-metal structures often exhibit an economical advantage in terms of material and production costs [71]. A conventional process chain of those hybrid structures consists of a deep drawing process of the sheet metal and the application of FRTP components (e.g., organic sheets or unidirectional

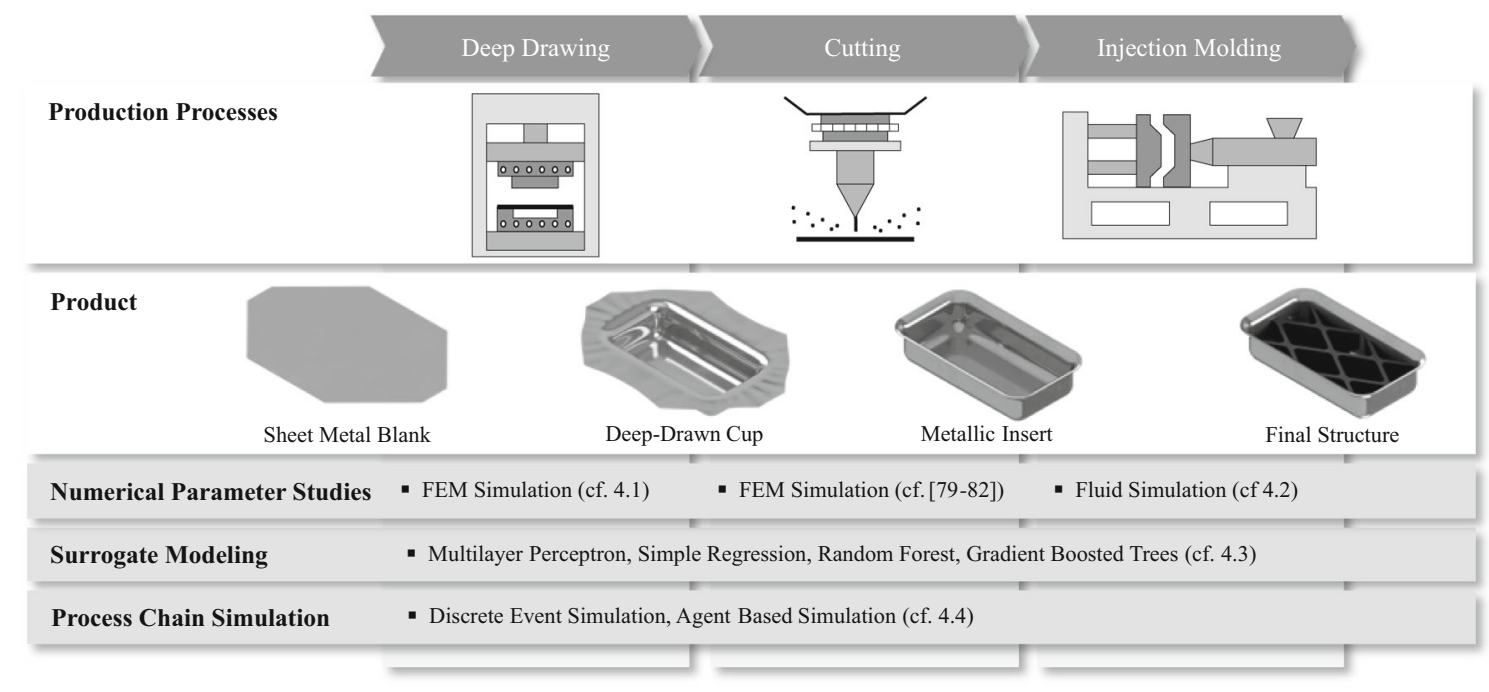

Fig. 7 Schematic view of the investigated process chain within the case study, the corresponding intermediate products, and the methods applied 
laminates) in a second thermoforming process [72]. Volumetric reinforcements can be realized by compression molding of long fiber reinforced thermoplastics or injection molding of SFRTP [73]. Novel process chains for intrinsic hybrid structures are given in [74]. The combination of different process steps consequently leads to challenges in terms of integrated simulation methods [75].

At the research factory Open Hybrid LabFactory in Wolfsburg (OHLF), Germany, [76] integrated manufacturing processes for MMLS in high-volume applications are investigated. In the present use case, the MMLS consists of a sheet metal cup in combination with SFRTP reinforcements. The investigated process chain, the intermediate product, and the methods used are depicted in Fig. 7. The design of the final structure is chosen for demonstration purposes following the geometries investigated in [77, 78].

The use case description is divided into four sections representing the different simulation methods applied at each level. Hereby, the focus is on the forming and molding process. In 4.1 , a numerical parameter study analyzing process influences on deep drawing is carried out. The subsequent cutting process is neglected in the numerical analysis. However, the integration into ICPPE is generally possible. Modeling approaches for different cutting processes can be found in e.g. [79-82]. The resulting metal cup is then used as a part insert in the injection molding process. The corresponding numerical parameter study on temperature influences during the overmolding is described in 4.2. The data obtained from both numerical studies are used to train the surrogate model in 4.3. Different machine learning methods are evaluated and compared. Finally, in 4.4, the process chain simulation is carried out to investigate cycle times and energy demands.

\subsection{Parametric study on deep drawing}

First, a numerical simulation for deep drawing of a rectangular cup was modeled. Deep drawing is one of the most important and proven sheet metal forming processes. Based on this example, a parameter study is carried out varying the blank holder force and the punch speed. The corresponding parameters provide input for the surrogate models and process chain simulation in the further process of this article.

\subsubsection{Material and model}

Conventional deep drawing steel DX56 was applied as a material, which is mainly used in automotive body design. The low-carbon deep drawing steel shows a purely ferritic microstructure that ensures a good slipping of grains to achieve a good formability. The sheet thickness of the material is $h=1.2 \mathrm{~mm}$. To determine the mechanical properties and the flow curves that are required for
Table 1 Material-specific parameters of DX56 for different strain rates

\begin{tabular}{lllll}
\hline$\dot{\varphi}$ & $\mathrm{A}$ & $\mathrm{B}$ & $\mathrm{C}$ & $\mathrm{D}$ \\
\hline $1 \mathrm{~s}^{-1}$ & $1650 \mathrm{MPa}$ & 0.025715 & 0.07019 & $1106 \mathrm{MPa}$ \\
$0.1 \mathrm{~s}^{-1}$ & $2530 \mathrm{MPa}$ & 0.02578 & 0.04247 & $1995 \mathrm{MPa}$ \\
$0.01 \mathrm{~s}^{-1}$ & $2115 \mathrm{MPa}$ & 0.01366 & 0.04191 & $1620 \mathrm{MPa}$ \\
\hline
\end{tabular}

the simulation, tensile tests were carried out at room temperature. Furthermore, three strain rates $\dot{\varphi}=0.01 \mathrm{~s}^{-1}$, $0.1 \mathrm{~s}^{-1}$, and $1 \mathrm{~s}^{-1}$ were tested. These are generally used for deep drawing applications. In the tensile test, only true stress values up to the beginning of the necking can be evaluated accurately. However, higher strains can be achieved at deep drawing processes. Therefore, values are also necessary for the further progression of the plastic strain. Thus, the experimental results were extrapolated by means of different model approaches to consider advanced plastic work behavior, where for DX56 the model approach of Ghosh (cf. [83]):

$k_{f, G h o s h}(\varphi)=A \cdot(B+\varphi)^{C}-D$

provides a good qualitative agreement. Therein $k_{f, G h o s h}$ corresponds to the true stress, $\varphi$ to the effective plastic strain and $A, B, C, D$ to the derived material-specific parameters given in Table 1.

The resulting flow curves are presented in Fig. 8. The diagram shows a comparison between experimentally measured and extrapolated flow curves depending on different strain rates. It can be seen that with increasing strain rate the strain hardening rises. However, this influence decreases with higher strain rates. The remaining physical and mechanical properties, which have been used within the numerical study, are summarized in Table 2.

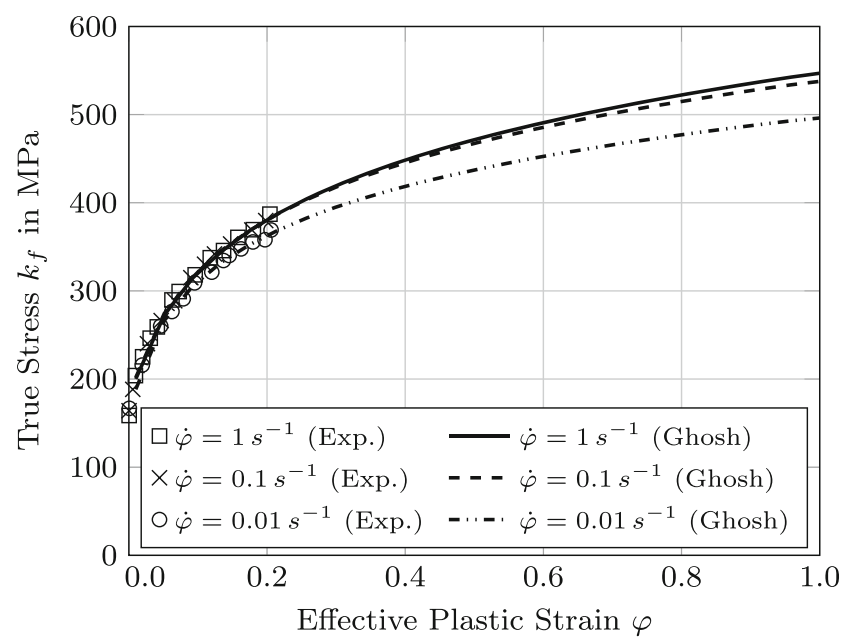

Fig. 8 Approximated flow curves of DX56 according to Ghosh (1) in comparison to the experimental values for the strain rates $\dot{\varphi}=1 \mathrm{~s}^{-1}$, $\dot{\varphi}=0.1 \mathrm{~s}^{-1}$ and $\dot{\varphi}=0.01 \mathrm{~s}^{-1}$ 
Table 2 Physical and mechanical properties of DX56

\begin{tabular}{llllll}
\hline Young's modulus & Poisson's ratio & Yield stress & Density & Specific heat & Thermal conductivity \\
$E$ & $v$ & $R_{p 0.2}$ & $\rho$ & $c_{p}$ & $\lambda$ \\
\hline $211 \mathrm{GPa}$ & 0.29 & $172 \mathrm{MPa}$ & $7.8 \mathrm{~g} / \mathrm{cm}^{3}$ & $460 \mathrm{~J} / \mathrm{kg} \mathrm{K}$ & $29 \mathrm{~W} / \mathrm{m} \mathrm{K}$ \\
\hline
\end{tabular}

The simulation of the deep drawing process was created in LS-DYNA and an explicit time integration has been used. As material model MAT_24 is chosen describing an elasto-plastic material behavior with an arbitrary stress versus strain curve and strain rate dependency. In order to consider the strain rate dependence, a table function was used. The table defines for each strain rate value a flow curve giving the stress versus effective plastic strain for that rate [84]. By means of the presented properties, the model got parameterized. It already has been validated for DX56 within the context of [85]. The tool selection as well as the cutting of the sheet metal was chosen by means of the sheet thickness. Thus, the functional surfaces were derived from the existing CAD data and meshed as shell elements.

The general structure of the simulation model and the initial blank are shown in Fig. 9.

The displayed tools consist of blank holder, die, and punch (left). The sheet metal blank (right) is clamped between blank holder and die with a defined force $F_{b h}$. The mesh of the blank consists of 13,300 elements and 13,403 nodes. During the test procedure, the punch is deep drawing the blank with a constant speed $v_{p}$ through the cavity of the die. The punch has a rectangular body with the dimensions $160 \mathrm{~mm} \times 80 \mathrm{~mm}$. All tools are modeled as rigid bodies. For friction, the standard value for sheet metal forming of $\mu=0.15$ has been applied. In the parametric study, the process parameters blank holder force $F_{b h}$ and punch speed $v_{p}$ are varied according to Table 3 .

Therefore, $F_{b h}$ was varied starting from $50 \mathrm{kN}$ in $10 \mathrm{kN}$ increments to $200 \mathrm{kN}$ at a constant punch speed of 20 $\mathrm{mm} / \mathrm{s}$. In the second step, $v_{p}$ was varied in steps of $10 \mathrm{~mm} / \mathrm{s}$ between 20 and $60 \mathrm{~mm} / \mathrm{s}$ with a blank holder force $F_{b h}=$ $100 \mathrm{kN}$. In order to reduce the computation time, the process time in the simulation was scaled down. To guarantee the accuracy of the results and to avoid influences on the

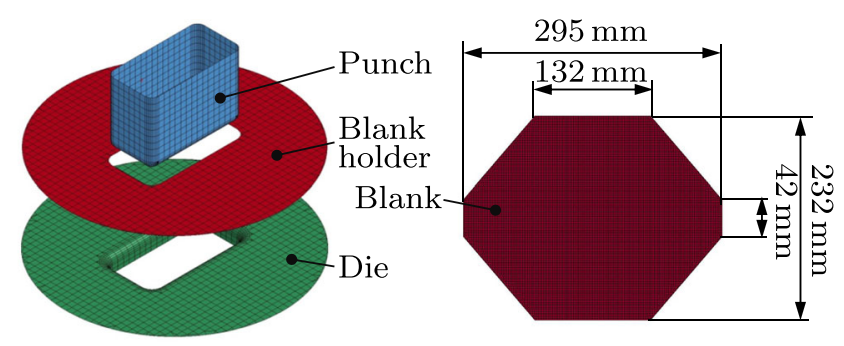

Fig. 9 General structure of the simulation model used for parametric study process chain, all time-dependent variables were scaled, as well. Exemplary simulations without time scaling showed no differences in the results. For the process chain simulation in 4.4, the unscaled time is used to compute the corresponding cycle times. In total, 20 simulations were carried out. Each simulation was stopped after reaching the drawing depth of $d=40 \mathrm{~mm}$, so that comparable parts are available.

\subsubsection{Numerical results}

First, the punch forces and the duration of the deep drawing process were evaluated as a function of the process parameters that are supposed to be applied in the process chain simulation. These data are used in Section 4.4 for the demand of machine components. Thus, the amount of energy required for forming can be estimated. Figure 10 shows the maximum punch force $F_{p, \max }$ achieved during deep drawing and the punch force in the last stage $F_{p}$, final for the various blank holder forces.

The diagram shows that with an increasing blank holder force, a higher maximum punch force is necessary to deep draw the blank at a constant speed of $v_{p}=20 \mathrm{~mm} / \mathrm{s}$. Due to higher holding pressure, less material flows, so the general resistance of the material during deep drawing increases. In the last stage, when the drawing depth of $d=40 \mathrm{~mm}$ is reached, the force $F_{p \text {, final }}$ decreases as a result of the strong thinning of the cup wall.

Figure 11 shows how the maximum punch force changes at different punch speeds. With increasing punch speed, the process works faster to reach the prescribed drawing depth of $d=40 \mathrm{~mm}$. Due to strain rate dependence, the maximum punch force rises with higher punch speed. Also, strong thinning of the cup wall takes places as the process accelerates.

Table 3 Overview of the varied process parameters in the simulation

\begin{tabular}{|c|c|c|c|c|c|}
\hline \multirow[t]{2}{*}{$v_{p}$ in $\mathrm{mm} / \mathrm{s}$} & \multicolumn{5}{|c|}{$F_{b h}$ in $\mathrm{kN}$} \\
\hline & 50 & $60 \ldots 90$ & 100 & $110 \ldots 190$ & 200 \\
\hline 20 & $X$ & $X$ & $X$ & $X$ & $X$ \\
\hline 30 & & & $X$ & & \\
\hline 40 & & & $X$ & & \\
\hline 50 & & & $X$ & & \\
\hline 60 & & & $X$ & & \\
\hline
\end{tabular}




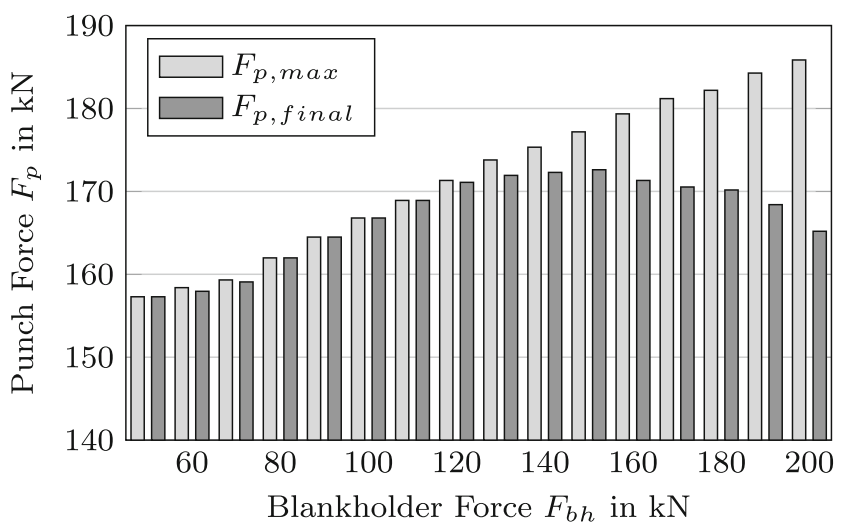

Fig. 10 Punch force vs. blank holder force

For the data analysis in Section 4.4, the last stage of the deep drawing process was evaluated. From each simulation, the $x-, y$-, and $z$-coordinates of all nodes of the blank were plotted. Furthermore, for each element of the blank, the parameters effective plastic strain $\varphi$, von Mises stress $\sigma_{v M}$, and the thickness $t$ were exported. Figure 12 shows exemplary results of the simulations for elevated blank holder forces.

In the surrogate modeling, all shown parameters are taken into account. The matrix can be extended at any time. In general, it can be seen that with an increasing blank holder force the blank is clamped more strongly. As a result, the flange is not drawn insufficiently. This has an influence on all shown parameters. The effective plastic strain $\varphi$ and von Mises stress $\sigma_{v M}$ at $50 \mathrm{kN}$ mainly show maximum values in the corners of the cup. This is where the cup thins out the most. With increasing blank holder force, maximum values of plastic strain, stress, and shell thickness are moving in the direction of the cup wall. In the case of shell thickness, differences can be observed in the flange area, as well. As the blank holder force decreases, more material flows from the flange into the cup wall. Therefore, radial tension stress and tangential compression stress are increasing. This causes a thickening of the material in the edge area of the flange. At $200 \mathrm{kN}$, a thickening is prevented, which means

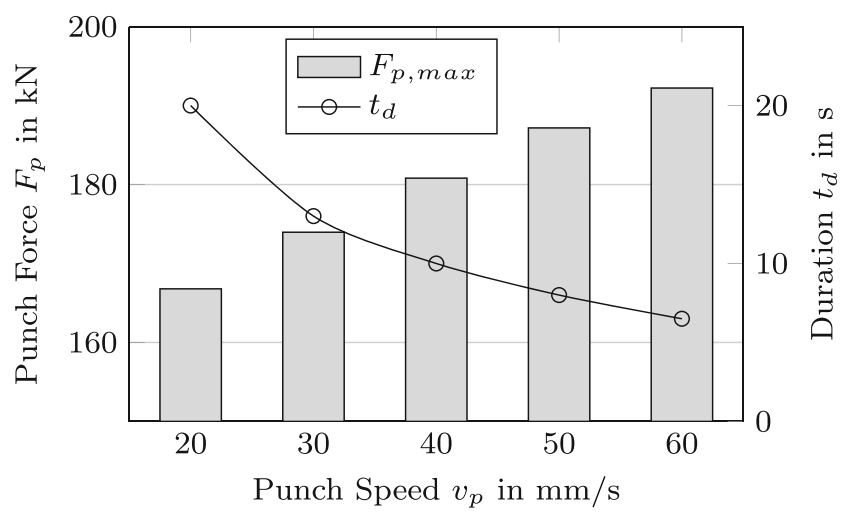

Fig. 11 Punch force and test duration vs. punch speed
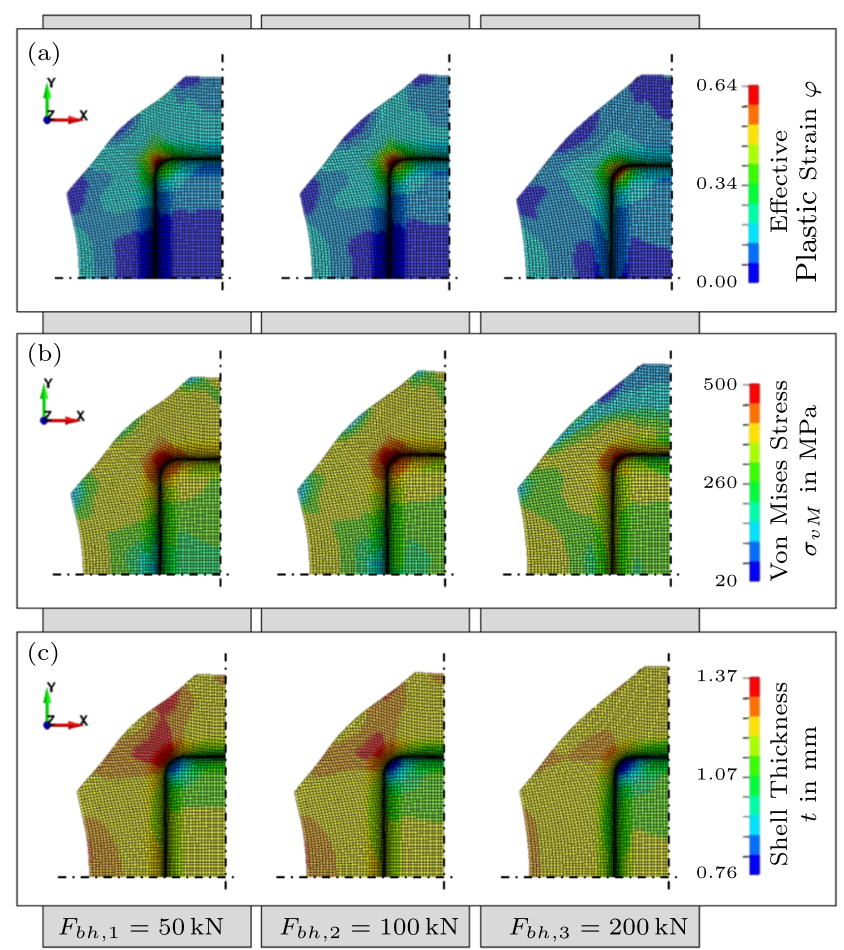

Fig. 12 Effective plastic strain (a), von Mises stress (b), and shell thickness (c) for blank holder forces of $F_{b h, 1}=50 \mathrm{kN}, F_{b h, 2}=$ $100 \mathrm{kN}$, and $F_{b h, 3}=200 \mathrm{kN}$

that the shell thickness remains at its initial value of $h=$ $1.2 \mathrm{~mm}$. In order to get an overview of the distribution of the sheet thickness, the global maximum and minimum values were written out and shown in Fig. 13 as a function of the process parameters.

Depending on the punch speed, the maximum sheet thickness remains constant at $t \approx 1.3 \mathrm{~mm}$. This is the area in the flange that increases in thickness. The minimum sheet thickness, on the other hand, decreases further with an increasing punch speed. For $v_{p}>30 \mathrm{~mm} / \mathrm{s}$, the strain rate dependence leads to significant thinning of the cup wall. A similar behavior can be observed as a function of the blank holder force. Both the maximum and the minimum shell thickness are decreasing with rising forces due to the reduction of radial and tangential stresses in the flange. The minimum shell thickness drops very sharply between $F_{b h}=110 \mathrm{kN}$ and $F_{b h}=150 \mathrm{kN}$. For these parameter sets, the cup wall begins to thin more strongly because the pressure in the flange is sufficient to prevent the material from flowing any further.

\subsection{Overmolding}

The analysis of the injection molding process is performed using Autodesk Moldflow [86]. The geometric model setup is depicted in Fig. 14. 


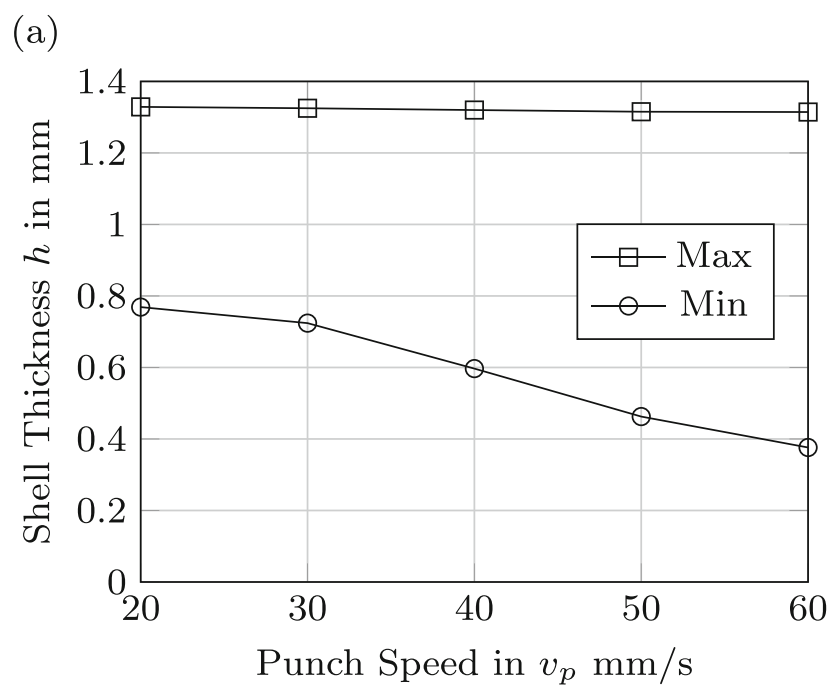

(b)

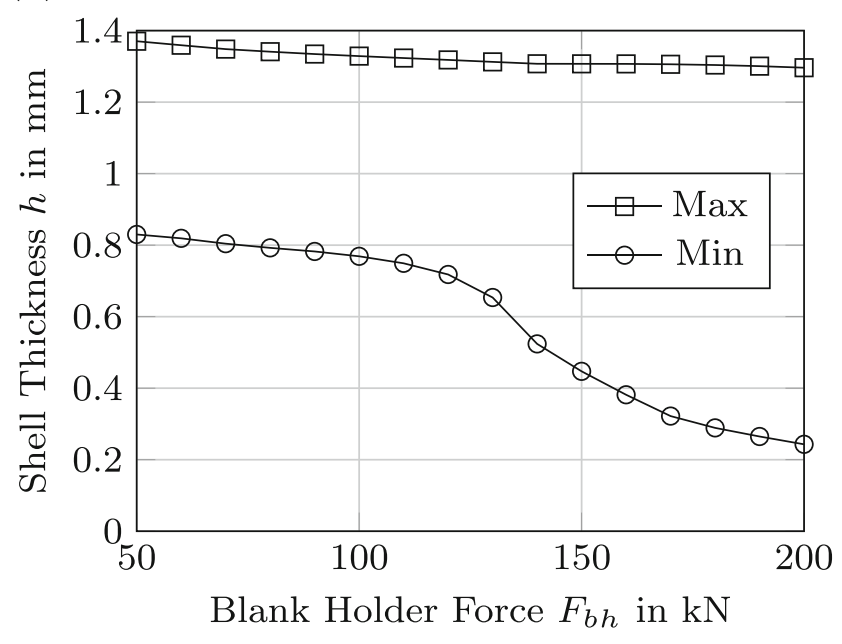

Fig. 13 Shell thickness vs. punch speed at $F_{b h}=100 \mathrm{kN}$ (a), shell thickness vs. blank holder force at $v_{p}=20 \mathrm{~mm} / \mathrm{s}(\mathbf{b})$

\subsubsection{Material and model}

The displayed model consists of two volume bodies representing the mold cavity (black) and the metallic insert part (gray). For both parts, tetrahedral elements are used, where the mold cavity is discretized with eight elements over the wall thickness to ensure a fine grid for the plastic flow analysis. The injection location (yellow) is placed in the center. The sheet metal insert has been modeled with a constant

(a)

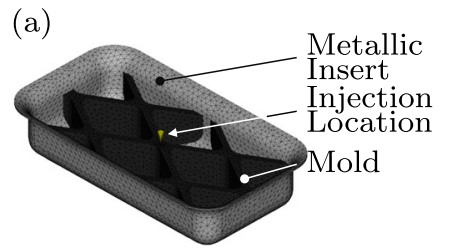

(b)

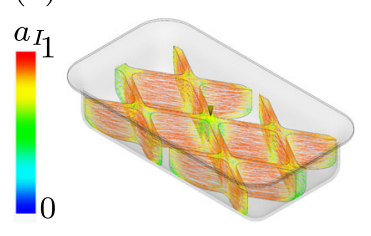

Fig. 14 Model setup and first eigenvector $a_{I}$ of orientation tensor a

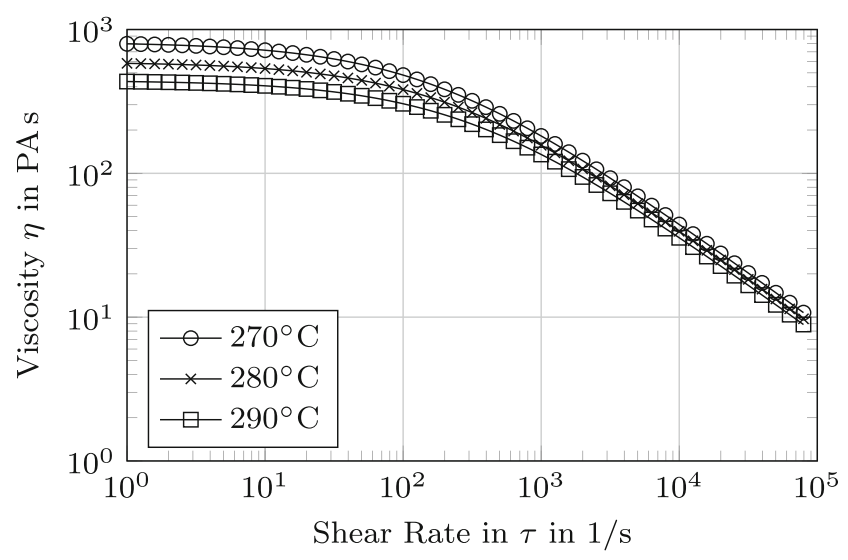

Fig. 15 Viscosity over shear rate for the used SFRTP from Moldflow material database [86]

sheet thickness of $1.2 \mathrm{~mm}$. The initial temperature is set constant to room temperature. The contact time between mold surface and insert is set $5 \mathrm{~s}$ before the injection starts. This ensures that the temperature of the metallic insert is high enough to prevent a fast solidification of the plastic melt when in contact with the insert. The mechanical and thermal properties of the insert are summarized in Table 2. For the analysis of the fluid flow, the Cross-WLF viscosity [87] model is used. Therein, the melt viscosity:

$\eta=\frac{\eta_{0}}{1+\frac{\eta}{0} \dot{\gamma}_{\tau^{*}}^{1-n}}$

is described by the shear rate $\dot{\gamma}$, an critical stress level $\tau^{*}$ and a power law index $n$. The Newtonian limit:

$\eta_{0}=D_{1} \exp \left[-\frac{A_{1}\left(T-T^{*}\right)}{A_{2}+\left(T-T^{*}\right)}\right]$

with $A_{2}=A_{3}+D_{3} p$, the glass transition temperature $T^{*}=D_{2}+D_{3} p$ and the pressure $p$ is described by material specific coefficients $A_{1}, A_{3}, D_{1}, D_{2}$, and $D_{3}$. In this study, we use a polyamide 6 material with 30 mass- $\%$ glass fibers. In Fig. 15, the viscosity over shear rate is plotted for the listed parameters.

The Cross-WLF coefficients of the SFRTP used within the injection molding simulations are given in Table 4.

Table 4 Cross-WLF coefficients for the used SFRTP taken from Moldflow material database [86]

Parameters

\begin{tabular}{ll}
$n$ & 0.3 \\
$\tau^{*}$ & $137 \mathrm{MPa}$ \\
$D_{1}$ & $1.5 \mathrm{e}+15 \mathrm{MPas}$ \\
$D_{2}$ & $333 \mathrm{~K}$ \\
$D_{3}$ & $0 \mathrm{~K} / \mathrm{MPa}$ \\
$A_{1}$ & 43.8 \\
$A_{3}$ & $51.6 \mathrm{~K}$ \\
\hline
\end{tabular}


The mechanical behavior of the final structure is mainly determined by the fiber orientation a within the SFRTP component. In the numerical analysis, it is computed by the Folgar-Tucker model [88-91] with a fiber interaction coefficient of $c_{a}=0.0156$.

For the parametric study, the mold temperature $T_{\text {Mold }}$ was varied in $10{ }^{\circ} \mathrm{C}$ increments between 70 and $100^{\circ} \mathrm{C}$. Within the DoE for the melt temperature $T_{\text {Melt }}$ the discrete values $270{ }^{\circ} \mathrm{C}, 280^{\circ} \mathrm{C}$ and $290^{\circ} \mathrm{C}$ are used. Hence, a virtual experiment with 12 simulations for the overmolding was set up.

\subsubsection{Numerical results}

The parametric study described above yields 12 virtual injection molding results. In the variation of mold and melt temperature already information in injection pressure and time are obtained. In Fig. 16a the injection pressure for the different melt temperature is plotted over the mold temperature. The maximum injection pressure $p_{I n j}$ of 10.4 MPa is computed at $T_{\text {Mold }}=70^{\circ} \mathrm{C}$ and $T_{\text {Melt }}=$ $270^{\circ} \mathrm{C}$. The lowest injection pressure is computed for the parameter combination $T_{\text {Mold }}=100^{\circ} \mathrm{C}$ and $T_{\text {Melt }}=$ $290^{\circ} \mathrm{C}$. In general, the injection pressure increase with increasing mold and melt temperature. Regarding Fig. 15, this is obvious since the higher the temperature of the melt the lower the viscosity is. With a higher mold
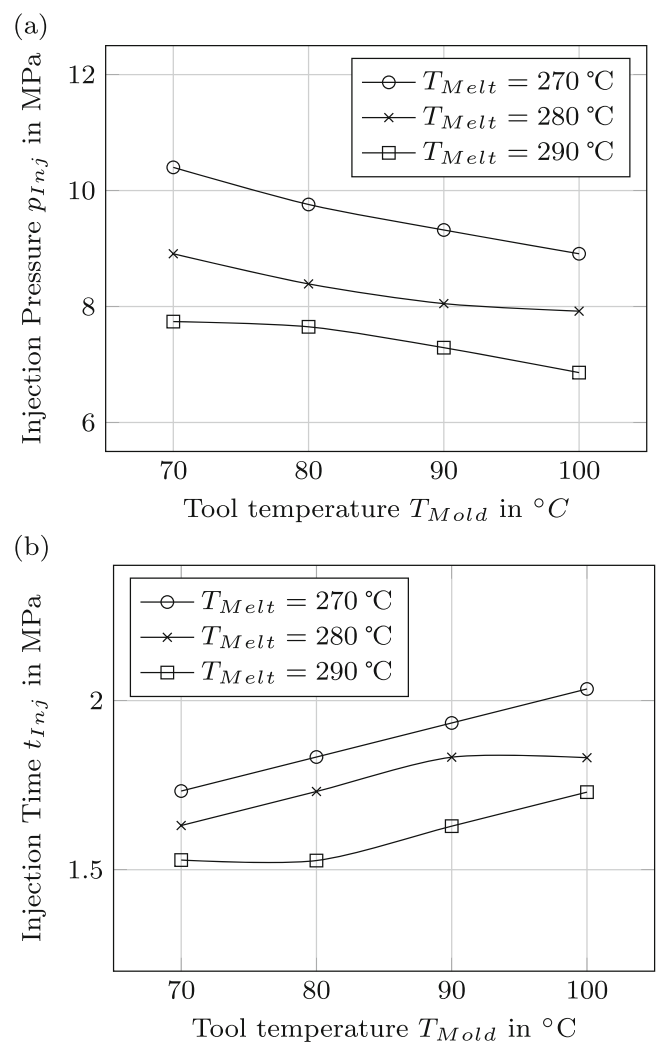

Fig. 16 Injection pressure over mold temperature (a), injection time over mold temperature (b) temperature the cooling of melt arises slower which leads to less viscosity and a better flow. Consequently, higher temperatures support the fluid flow. However, in Fig. 16b, the diagrams show an increase of the injection time with increasing mold temperature.

Besides the energy and time related global properties of the process, detailed information on local field variables is obtained. In the case of SFRTP, the fiber orientation determines the mechanical properties of the structure and yields anisotropic behavior. Hence, for each simulation result, the tensor of fiber orientation a, exemplary depicted in Fig. 14b, is exported and used for the subsequent data analysis to achieve a fast and robust surrogate model for the fiber orientation.

\subsection{FEM surrogate modeling}

According to the proposed framework of ICPPE, results of detailed FEA are used for adequate parametrization of process chain and factory simulation. In order to make FEM feasible for scenario analysis of the aforementioned simulations, FEM surrogate modeling is proposed. In the following, the method of FEM surrogate modeling is exemplary applied to a sheet metal cup that is reinforced by a plastic rib structure (see Sections 4.1 and 4.2).

\subsubsection{Modeling and input parameters}

Firstly, the sheet metal cup is deep drawn on a forming press. Afterwards, the plastic rib structure is integrated through fiber injection molding. For both processes, FEM simulations are performed, covering a specific DoE on process parameters (see Fig. 17). For deep drawing, the process parameters $50 \mathrm{kN} \leq F_{b h} \leq 200 \mathrm{kN}$ and punch speed $20 \mathrm{~mm} / \mathrm{s} \leq v_{p} \leq 60 \mathrm{~mm} / \mathrm{s}$ are analyzed. The FEM simulation delivers structure properties, like the deep drawn

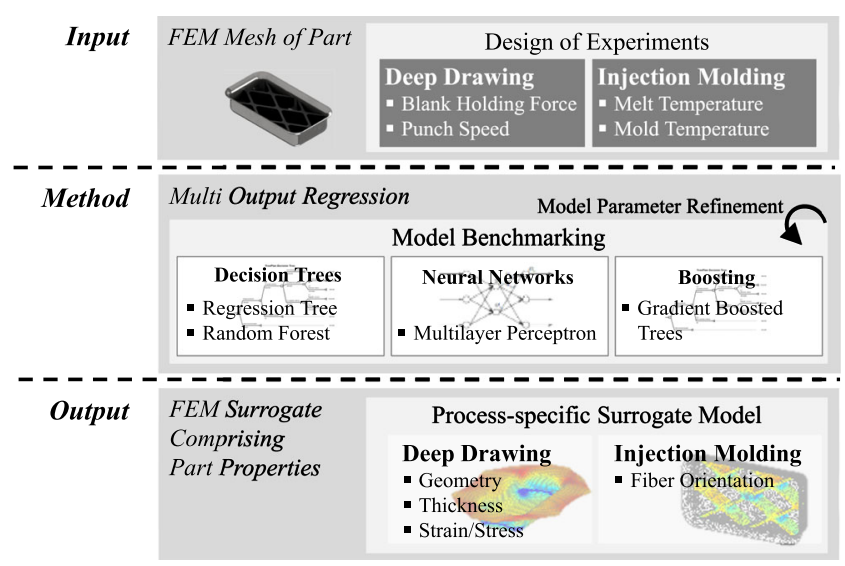

Fig. 17 Workflow for FEM surrogate modeling of a deep drawing and injection molding process 
geometry, wall thickness, strain, and stress, dependent on the parameters. The process-specific surrogate model for deep drawing should reflect these properties with a low error rate. Subsequently, for the fiber injection molding process, the FEM simulates the fiber orientation of the rib structure. The fiber orientation is described by the symmetric tensor a comprising the six elements $a_{x x}, a_{y y}, a_{z z}, a_{x y}, a_{x z}$, and $a_{y z}$, which makes the FEM surrogate modeling a multioutput regression task as well. Similar to deep drawing, two process parameters are evaluated in terms of a DoE for fiber injection molding. Firstly, the melt temperature $T_{M e l t}$, covering the temperature range of 270 to $290^{\circ} \mathrm{C}$ and secondly, the mold temperature $T_{M o l d}$, having a temperature zone from 70 to $100^{\circ} \mathrm{C}$. Supplementary to the process parameters, the FEM mesh of each part is considered input feature for modeling. Within this use case, the mesh for deep drawing consists of 13,300 elements; the rib structure is modeled by 12,240 nodes.

For deriving a generalized process-specific FEM surrogate model, nonlinear modeling techniques in the form of multi-output regression methods are deployed for mapping the features, i.e., mesh and parameters, to the target variables, i.e., part properties. The ability for FEM surrogate modeling of four machine learning methods (simple regression tree, random forest, multilayer perceptron, and gradient boosted trees) is tested for each process variant. In order to achieve low error rates, respectively high scores for $R^{2}$, a model parameter optimization, i.e., hyper parameter optimization, is performed. Table 5 lists the varied model parameters, their variation range, and the amount of variation steps for each method. Furthermore, the modeling results are evaluated through a 6-fold cross-validation, due to the prevention of overfitting and the target of deriving a generalized model for untested points within the parameter space. Table 5 also shows the best found model parameters. Interestingly, in injection molding, the best parameters for the methods simple regression tree and gradient boosted trees are found at the outer limit of the variation range, e.g., amount of trees $=260$ for gradient boosted trees. Hence, a further increase in $R^{2}$ could be expected when increasing the parameter limit.

\subsubsection{Results of surrogate modeling}

Results for $R^{2}$ of each part property and the original FEM model compared with those of the FEM surrogate model as a 3D plot are shown in Fig. 18 for each process variant. The 3D plot of the deep drawn part, which shows the wall thickness for $F_{b h}=110 \mathrm{kN}$ and $v_{p}=20 \mathrm{~mm} / \mathrm{s}$, reveals the well fit between the original FEM model (Fig. 18a) and its surrogate model built through a random forest (Fig. 18b). For example, the material withdrawal in the cup corner is precisely reproduced. Deviations between FEM and surrogate are located on the cups' short edge. The comparison of $R^{2}$ over all four regression methods (Fig. 18c) shows that the plotted wall thickness and strain and stress are the least correlated part properties, still reaching good values for $R^{2}$ for simple regression tree and random forest. On the contrary, the part property deep drawn geometry, i.e., XFinal, Y-Final, and Z-Final, yields the highest scores for $R^{2}$. A reason for this can be found in the small deviations of the final deep drawn geometry across the whole DoE. As for deep drawing, an exemplary plot for fiber injection molding of the plastic rib structure for the original FEM yielded by Moldflow (Fig. 18d) and the FEM surrogate model built through a random forest approach (Fig. 18e) is drawn for the fiber direction element $a_{x x}$. The underlying injection molding process parameters are melt temperature $T_{\text {Melt }}=270{ }^{\circ} \mathrm{C}$ and mold temperature $T_{\text {Mold }}=70^{\circ} \mathrm{C}$. Both plots show just minor deviations in the color hue. The bar plot for $R^{2}$ (Fig. 18f) emphasizes the good modeling

Table 5 Overview of deployed regression methods and their tested and best hyperparameters

\begin{tabular}{|c|c|c|c|c|c|}
\hline Method & Parameter & Variation range & \# variation steps & $\begin{array}{l}\text { Best parameters for } \\
\text { deep drawing }\end{array}$ & $\begin{array}{l}\text { Best parameters for injection } \\
\text { molding }\end{array}$ \\
\hline Multilayer & \# Layer & $1-6$ & 6 & 2 & 5 \\
\hline perceptron & \# Nodes & $1-40$ & 40 & 38 & 22 \\
\hline simple re- & Max. tree depth & $1-20$ & 20 & 19 & 20 \\
\hline gression tree & Min. node size & $1-50$ & 50 & 1 & 20 \\
\hline Random & $\#$ trees & $10-20$ & 11 & 15 & 19 \\
\hline \multirow[t]{2}{*}{ forest } & Max. tree depth & None & 1 & - & - \\
\hline & Min. node size & None & 1 & - & - \\
\hline Gradient & Learning rates & $0.2-0.8$ & 4 & 0.4 & 0.8 \\
\hline boosted & $\#$ trees & $100-260$ & 9 & 120 & 260 \\
\hline \multirow[t]{2}{*}{ trees } & Max. tree depth & 4 & 1 & - & - \\
\hline & $\alpha$ & 0.95 & 1 & - & - \\
\hline
\end{tabular}


(a)

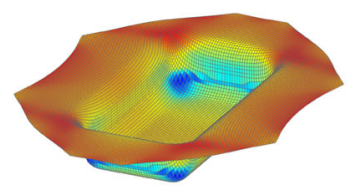

(d)

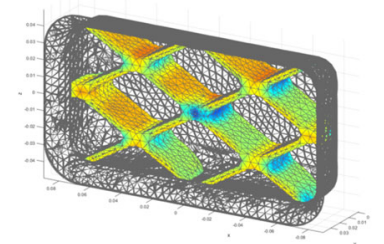

(b)

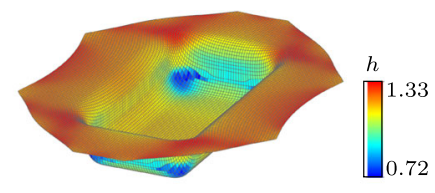

(e)

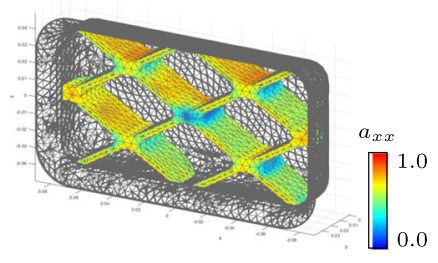

(c)

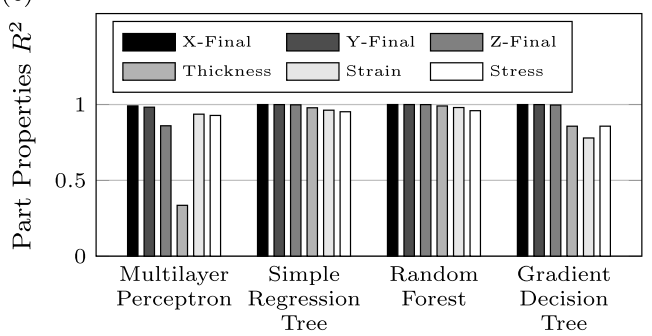

(f)

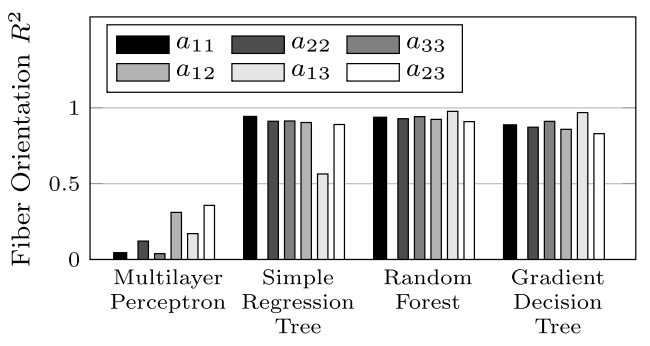

Fig. 18 Results for FEM surrogate modeling. Original wall thickness for deep drawing from LS-DYNA (a) and its surrogate through random forest as a 3D plot for blank holding force $F_{b h}=110 \mathrm{kN}$ and punch speed $v_{p}=20 \mathrm{~mm} / \mathrm{s}$ (b). Comparison of $R^{2}$ for all tested regression approaches for deep drawing $(\mathbf{c})$. Original fiber orientation

performance. Especially the random forest approach yields constant high scores for $R^{2}$ with a minimum of 0.909 for $a_{y z}$ and a maximum score of 0.977 for $a_{x z}$. The methods simple regression tree and gradient decision tree delivered similar modeling performance, just the multilayer perceptron approach performed weak for injection molding. The obtained process-specific FEM surrogate models are feasible to be applied for untried process parameter combinations in scenario analysis delivering adequate information on part properties for process chain and factory simulation.

\subsection{Process chain simulation}

The process chain contains an injection molding machine and a hydraulic press. The goal was to investigate the effect of parameter variation in the two processes on the overall process chain performance regarding lead times and energy intensities.

\subsubsection{Model logic and input parameters}

The process chain model starts with pre-cut steel sheets that enter the process chain at a hydraulic press for deep drawing. A buffer follows the press for the temporary storage of the formed sheets. The cutting step has not been modeled in detail. Rather, it is represented by a simple discrete event block. The reinforcing ribs are formed thereafter in an injection molding machine. The last process step is quality control, where reject parts are sorted out. $\left(a_{x x}\right)$ for fiber injection molding from Moldflow (d) and its surrogate through random forest approach as a $3 \mathrm{D}$ plot for $T_{\text {Melt }}=270^{\circ} \mathrm{C}$ and $T_{\text {Mold }}=70^{\circ} \mathrm{C}(\mathbf{e})$. Comparison of $R^{2}$ for all tested regression approaches for injection molding (f)

Bottom-up machine models are connected together with buffers and a quality control station to form a process chain model. The modeling environment for both the machine modeling and process chain modeling is AnyLogic. The models were developed combining the principles of agent based and discrete event simulation. Machines and products act in this modeling approach as agents with individual parameters, behavior, and communication interfaces to other agents. The product agents pass through a discrete event process chain that utilizes the machines as resources. After the machines are ready for production after rampup, the product agents are created and enter the process chain. When a product agent enters a machine agent, the machine agents start processing the product according to the defined process-specific steps. During each step, the electrical power is calculated based on the process parameters (e.g., temperature or processing time), machine parameters (e.g., efficiency of machine components) and product parameters (e.g., weight, material). The quality of the produced part is defined in each process step according to a probability distribution. If a reject part is produced, a new product agent is generated and sent to the process chain. The output parameters, such as direct energy demand, waiting time, or reject/good part, are stored in the product agent. After processing ended for the whole production batch including the additional parts due to reject parts, the indirect energy demand per part is calculated. To this end, the total indirect energy demand of the machines and direct energy demand of reject parts are allocated equally on all good parts. The machine models and the process chain 
Table 6 Parameters from the injection molding simulation used in the process chain simulation

\begin{tabular}{lll}
\hline Parameter & Dimension & Value \\
\hline Injection time & $\mathrm{s}$ & $1.5-2$ \\
Holding pressure time & $\mathrm{s}$ & 10 \\
Mold surface temperature & $\mathrm{K}$ & $343.2-373.2$ \\
Melt temperature & $\mathrm{K}$ & $543.2-563.2$ \\
Injection pressure & $\mathrm{MPa}$ & $6.6-9.9$ \\
Clamp force & $\mathrm{kN}$ & $46-71.1$ \\
Time to eject & $\mathrm{s}$ & $57.1-76.5$ \\
Total mass & $\mathrm{g}$ & $80.6-81.5$ \\
\hline
\end{tabular}

model are connected via a spreadsheet interface with the numerical process models.

Machine parameters were determined based on the machine pool at the OHLF. Process parameters were acquired based on a parametric study of the numerical process simulation of forming and injection molding. Tables 6 and 7 provide in this context an overview of the employed parameters and the respected intervals. Altogether, the parametric study provided twenty parameter sets for forming and twelve sets for injection molding. In the process chain simulation, all parameter set combinations were tested out; altogether 240 simulation runs were carried out. Remaining process parameters (that could not be retrieved from the process simulation) were defined according to typical process windows from literature and expert interviews.

The case study simulated the manufacturing of 100 parts. The quality rate of both machines was assumed to be $98 \%$, thus addressing also inefficiencies by reject parts that indirectly lead to an increase of the indirect energy demand of products. The goal was to illustrate the interdependencies between process parameters, which are decided on in the process simulation, and the product energy intensity as well as lead time.

\subsubsection{Results of the process chain simulation}

Figure 19 compares the minimum and maximum values of the cycle times on both machines. In an ideal case, the cycle

Table 7 Parameters from the deep drawing simulation used in the process chain simulation

\begin{tabular}{lll}
\hline Parameter & Dimension & Value \\
\hline Blank holder force & $\mathrm{kN}$ & $50-200$ \\
Forming speed & $\mathrm{mm} / \mathrm{s}$ & $20-60$ \\
Forming time & $\mathrm{s}$ & $6.5-20$ \\
Maximum forming pressure & $\mathrm{kN}$ & $157.3-192.2$ \\
\hline
\end{tabular}

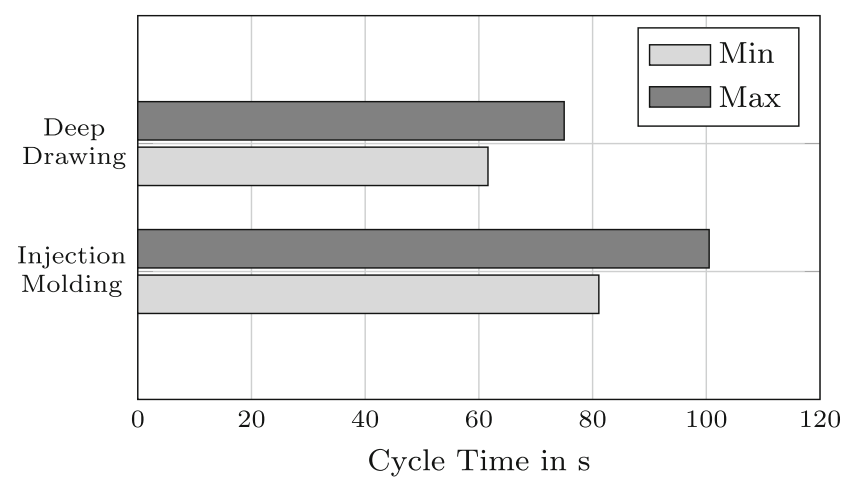

Fig. 19 Maximum and minimum of cycle times for each process

times are even or close to even at each process step. This is here however not the case since we choose a strong criterion for the cooling time. The cycle time of injection molding exceeds the cycle time of the press for all parameter sets. The higher cycle time on the injection molding machine causes a time bottleneck and drives the lead time of the production upwards. The case study illustrates however effectively that process time reduction on single-process steps does not necessarily lead to a reduced lead time. Instead, the whole process chain needs to be considered. In this case, the process time for injection molding should be minimized. The process time for deep drawing could even be longer without affecting the lead time negatively.

The cycle time difference between the two processes is represented in the composition of the lead time. Waiting time occurs while a product is stored temporarily in the buffer between the press and injection molding machine. The comparison of average processing times with average waiting times (see Fig. 20) illustrates the impact of uneven cycle times. The figure illustrates the shares of processing and waiting time for the minimum, average, and maximum lead time. In all three cases, the lead time is largely composed of waiting time with a share of up to $90 \%$. For the present use case, this indicates that cooling times seem to be too large and can most probably be reduced in order to reduce the waiting time. However, in order to decide

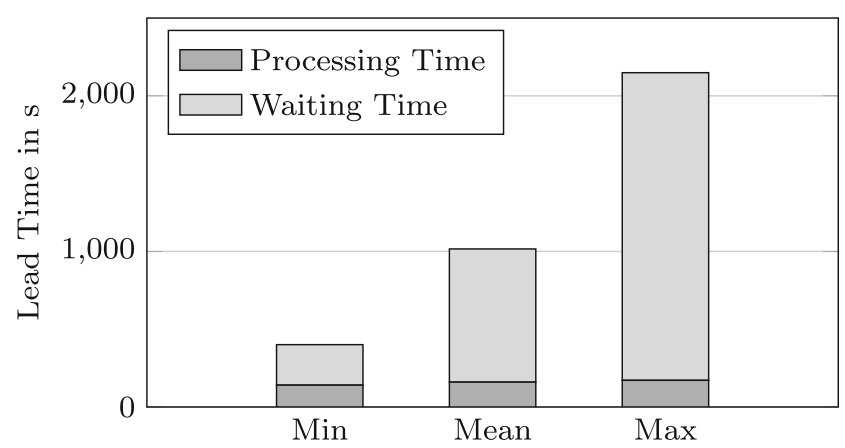

Fig. 20 Breakdown of lead time on processing and waiting time 


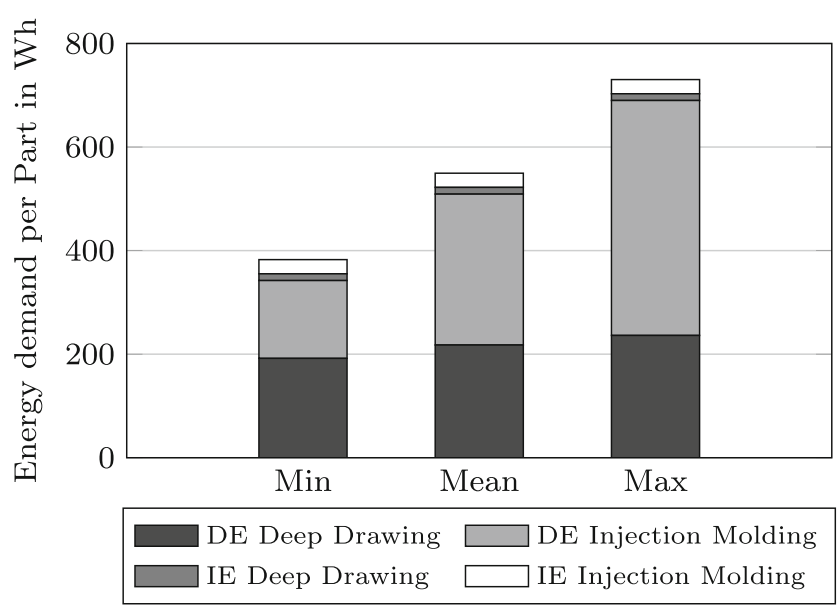

Fig. 21 Breakdown of value/non-value added energy demands on processes

whether the lead time is too high and needs to be reduced, it needs to be compared with the customer tact time. For the calculation of the customer tact time, further information regarding the working hours, working days, and customer demand is needed. Therefore, it has been excluded in this case study. Based on the customer tact time and the current lead time, further decisions can be made, e.g., whether a new machine should be installed to increase the output.

Figure 21 illustrates the highest, lowest, and average product energy intensity for all 240 simulation runs, broken down into direct and indirect energy demands. While direct energy demands are considered as value adding, indirect energy demands represent the share of non-value adding energy demand. The direct energy demand of one product represents the sum of each machine's energy demand in the processing state that is related to one good part. The direct energy demand of reject parts is assigned to the indirect energy demand. The indirect energy demand per part further includes the energy demand of the machines in the ramp-up and standby stages. As explained above, the buffer between the machines permits a high utilization without noteworthy waiting times of the machines. The indirect energy demand is consequently diminishing in comparison with the direct energy demand. Regarding the direct energy demand, the parameter variation on the injection molding machine shows an over $200 \%$ difference between the best and worst cases. In contrast to that, the difference on the hydraulic press stays below $1 \%$. This may be due to the higher range of process windows that were applied on the injection molding machine.

The initial concern of the case study on the process chain level was to investigate the interdependencies between the lead time and product energy intensity. This should help product, process, and factory planners to design a product and production system that fits best economic and environmental targets. Figure 22 illustrates the relation

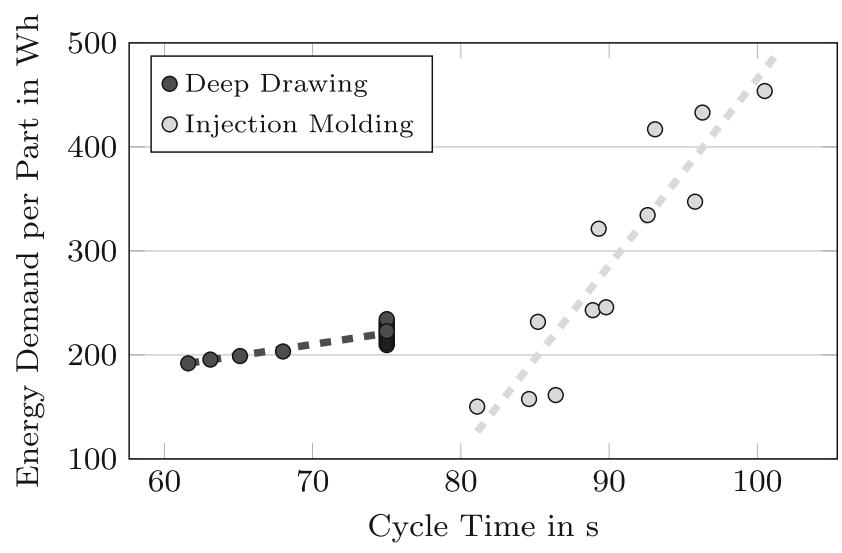

Fig. 22 Comparison of the direct energy demand of deep drawing and injection molding with the cycle time

between the cycle times of the process steps and the resulting direct energy demand on the press and injection molding machine. It confirms the abovementioned small variation of the direct energy demand on the press. The results indicate that the energy demand per part increases only slightly with a higher process time.

The injection molding machine shows contrast to that a much higher effect. A higher cycle time seems to lead to a higher direct energy demand. This is a favorable effect, as the cycle time of the injection molding machine needs to be minimized in order to reduce the difference between the two process steps. This way, not only the lead time can be reduced, but also the energy demand of the injection molding machine. It should be noted that not all process parameter sets with a lower cycle time lead to a reduction in the energy demand. In order to explore the contribution of the input parameters to the energy intensity in detail, further parameter studies are needed.

In conclusion, the process chain simulation enhanced with the integration of numeric process simulation results can support planning processes in production engineering. It can contribute to understanding the effects of process parameter variation on the whole process chain and explore different scenarios regarding lead times and energy demands.

\section{Concluding remarks}

Driven by the trend of industrial digitization, likewise product and production engineering involve more and more virtual and digital methods in order to increase the efficiency, shorten development times, and reduce prototyping for a shorter and cost-efficient time to market. The usage of virtual methods allows the parallelization of different engineering steps in concurrent engineering within the product development process. However, this requires an integrated 
simulation concept that allows the exchange of data of each numerical analysis. This paper illustrates an integrated simulation modeling approach for engineering and assessing new manufacturing processes, exemplified by the use case of MMLS. The multi-scale modeling approach (i.e., product, process, process chain, and factory level) was prototypically implemented and its functionality demonstrated at an exemplary process chain. Results of parametric studies on the process level have been used as input for a machine learning-based surrogate model that allows a fast and accurate search across the underlying design space. In this way, the surrogate models can offer accurate product properties at different process setting values for process chain simulation within milliseconds. Supplementary results like processing time and energy consumption obtained on the process level are used as further input for process chain modeling for an integrated computational approach. Thus, ICPPE provides a multi-scale framework to link design and the production phase more closely.

The interaction between the different levels and the corresponding parameters allows a bottom-up engineering of all relevant manufacturing steps throughout the process chains. By methods of computational engineering each process and the product itself are virtually verified. The information obtained is transferred to the process chain level to fulfill a multi-criteria assessment and planning of the individual process chains and the factory. Due to the continuity, also top-down developments can be fulfilled. Hence, it is possible to estimate whether an existing factory with its TBS is suited for the production of a certain product. Such procedure is often present when MMLS are introduced into new product concepts but existing machines and production lines need to be used. However, the integrated approach can be applied to all fields of product development and supports both the product engineering and the production engineering. Furthermore, by adding and training continuously surrogate models at the different levels, fast prediction tools are available. They can be used efficiently for optimization tasks during the development phase or as quality measures during the operating phase.

The combination of sophisticated surrogate models together with detailed finite element simulations and agentbased or discrete event simulations depicted in the concept of ICPPE (Fig. 2) has great potential to realize an integrated computational product and production engineering in product development.

Acknowledgements This research and results published are based on the research program MoBILISE funded by the Ministry of Science and Culture of Lower Saxony and the Volkswagen Foundation.

Funding Open Access funding provided by Projekt DEAL.
Open Access This article is licensed under a Creative Commons Attribution 4.0 International License, which permits use, sharing, adaptation, distribution and reproduction in any medium or format, as long as you give appropriate credit to the original author(s) and the source, provide a link to the Creative Commons licence, and indicate if changes were made. The images or other third party material in this article are included in the article's Creative Commons licence, unless indicated otherwise in a credit line to the material. If material is not included in the article's Creative Commons licence and your intended use is not permitted by statutory regulation or exceeds the permitted use, you will need to obtain permission directly from the copyright holder. To view a copy of this licence, visit http:// creativecommonshorg/licenses/by/4.0/.

\section{References}

1. Rix J, Haas S, Teixeira J (eds) (1995) Virtual prototyping: virtual environments and the product design process. Springer, Boston

2. Cerdas F, Thiede S, Herrmann C (2018) Integrated computational life cycle engineering - application to the case of electric vehicles. CIRP Ann 67(1):25-28. https://doi.org/10.1016/j.cirp.2018. 04.052

3. Allison J, Backman D, Christodoulou L (2006) Integrated computational materials engineering: a new paradigm for the global materials profession. JOM 58(11):25-27. https://doi.org/10.1007/ s11837-006-0223-5

4. Panchal JH, Kalidindi SR, McDowell DL (2013) Key computational modeling issues in Integrated Computational Materials Engineering. Comput Aided Des 45(1):4-25. https://doi.org/10. 1016/j.cad.2012.06.006

5. Bleck W, Brecher C, Herty M, Hirt G, Hopmann C, Klocke F, Borchmann N, Dierdorf J, Farivar H, Fayek P, Häck A, Kripak V, Krömer M, Laschet G, Prahl U, Rüngeler M, Schmitz GJ, Spekowius M, Springer P, Teixeira AM (2017) Integrated computational materials and production engineering (ICMPE). In: Brecher C, Özdemir D (eds) Integrative production technology: theory and applications. Springer International Publishing, Cham, pp 253-364

6. Mourtzis D, Doukas M, Bernidaki D (2014) Simulation in manufacturing: review and challenges. Procedia CIRP 25:213229. https://doi.org/10.1016/j.procir.2014.10.032

7. Herrmann C, Dewulf W, Hauschild M, Kaluza A, Kara S, Skerlos S (2018) Life cycle engineering of lightweight structures. CIRP Ann 67(2):651-672. https://doi.org/10.1016/j.cirp.2018.05.008

8. Fleischer J, Teti R, Lanza G, Mativenga P, Möhring HC, Caggiano A (2018) Composite materials parts manufacturing. CIRP Ann 67(2):603-626. https://doi.org/10.1016/j.cirp.2018.05.005

9. Görthofer J, Meyer N, Pallicity TD, Schöttl L, Trauth A, Schemmann M, Hohberg M, Pinter P, Elsner P, Henning F, Hrymak A, Seelig T, Weidenmann K, Kärger L, Böhlke T (2019) Motivating the development of a virtual process chain for sheet molding compound composites. PAMM 19(1):e201900124. https://doi.org/10. 1002/pamm.201900124

10. Grossmann IE, Westerberg AW (2000) Research challenges in process systems engineering. AIChE J 46(9):1700-1703. https:// doi.org/10.1002/aic.690460902

11. Cameron IT, Ingram GD, Hangos KM (2008) Multiscale process modeling. In: Computer aided process and product engineering. Wiley, pp 189-221. https://doi.org/10.1002/9783527619856.ch7

12. Sengupta D, Abraham JP, Ceja M, Gonzalez MA, Ingwersen WW, Ruiz-Mercado GJ, Smith RL (2015) Industrial process system assessment: bridging process engineering and life cycle 
assessment through multiscale modeling. J Clean Prod 90:142152. https://doi.org/10.1016/j.jclepro.2014.11.073

13. Borshchev A, Filippov A (2004) From system dynamics and discrete event to practical agent based modeling: reasons, techniques, tools. In: Proceedings of the 22nd international conference of the system dynamics society, vol 22

14. Schönemann M, Bockholt H, Thiede S, Kwade A, Herrmann C (2019) Multiscale simulation approach for production systems. International Journal of Advanced Manufacturing Technology 38(1):81. https://doi.org/10.1007/s00170-018-3054-y

15. Thiede S, Seow Y, Andersson J, Johansson B (2013) Environmental aspects in manufacturing system modelling and simulationstate of the art and research perspectives. CIRP J Manuf Sci Technol 6(1):78-87. https://doi.org/10.1016/j.cirpj.2012.10.004

16. Thomitzek M, von Drachenfels N, Cerdas F, Herrmann C, Thiede S (2019) Simulation-based assessment of the energy demand in battery cell manufacturing. Procedia CIRP 80:126131. https://doi.org/10.1016/j.procir.2019.01.097

17. Sobottka T, Kamhuber F, Sihn W (2017) Increasing energy efficiency in production environments through an optimized, hybrid simulation-based planning of production and its periphery. Procedia CIRP 61:440-445. https://doi.org/10.1016/j.procir. 2016.11.151

18. Zienkiewicz O, Taylor R, Fox D (eds) (2014) The finite element method for solid and structural mechanics, 7th edn. ButterworthHeinemann, Oxford

19. Zienkiewicz O, Taylor R, Nithiarasu P (eds) (2014) The finite element method for fluid dynamics, 7th edn. ButterworthHeinemann, Oxford

20. Behrens BA, Bouguecha A, Sidhu KB, Matthias T, Peshekhodov I (2011) New strategies in finite element analysis of material processing. Lecture Notes in Applied and Computational Mechanics 57: Modelling, Simulation and Software Concepts for ScientificTechnological Problems 57. https://doi.org/10.1007/978-3-64220490-6

21. Tekkaya A (2000) State-of-the-art of simulation of sheet metal forming. J Mater Process Technol 103(1):14-22. https://doi.org/ 10.1016/S0924-0136(00)00413-1

22. Haepp HJ, Rohleder M (2005) FE simulation of sheet metal forming - state of the art in automotive industry. Advanced Materials Research 6-8:13-18. https://doi.org/10.4028/www.scientific. net/AMR.6-8.13

23. Roll K (2008) Simulation of sheet metal forming - necessary developments in the future

24. Behrens BA, Voges-Schwieger K (2010) Qualitative analyse verschiedener Verfahren zur Ermittlung der rückfederung: qualitative analysis of different methods for the determination of springback evaluation, Forschung für die Praxis P, vol 768. Verl. und Vertriebsges. mbH, Düsseldorf

25. Behrens BA, Bouguecha A, Sabitovic A (2010) Einfluss des Verfestigungsgesetzes auf die Ergebnisse der Rückfederungssimulation von hochfesten Tiefziehstählen

26. Behrens BA, Bouguecha A, Hadifi T, Mielke J (2011) Advanced friction modeling for bulk metal forming processes. Prod Eng 5(6):621-627. https://doi.org/10.1007/s11740-011-0344-8

27. Behrens BA, Lorenz R (2019) Erweiterung der Modellierung der wärmefreisetzungsrate für stähle. EFB-Forschungsbericht $\mathrm{Nr} 521$

28. Hieber CA, Shen SF (1980) A finite-element/finite-difference simulation of the injection-molding filling process. J NonNewtonian Fluid Mech 7(1):1-32. https://doi.org/10.1016/03770257(80)85012-9

29. Austin C (1981) Improving the design of injection molds and parts using computer simulation of plastic flow. In: International pacific conference on automotive engineering, SAE International. https://doi.org/10.4271/811414
30. Dimla DE, Camilotto M, Miani F (2005) Design and optimisation of conformal cooling channels in injection moulding tools: AMPT/AMME05 Part 2. J Mater Process Technol 164-165:12941300. https://doi.org/10.1016/j.jmatprotec.2005.02.162

31. Kitayama S, Miyakawa H, Takano M, Aiba S (2017) Multiobjective optimization of injection molding process parameters for short cycle time and warpage reduction using conformal cooling channel. The International Journal of Advanced Manufacturing Technology 88(5):1735-1744. https://doi.org/10.1007/s00170016-8904-x

32. Spina R (2004) Injection moulding of automotive components: comparison between hot runner systems for a case study: Proceedings of the International Conference on Advances in Materials and Processing Technologies: Part 2. J Mater Process Technol 155156:1497-1504. https://doi.org/10.1016/j.jmatprotec.2004.04.359

33. Lee KS, Lin JC (2006) Design of the runner and gating system parametersfor a multi-cavity injection mould using FEM and neural network. The International Journal of Advanced Manufacturing Technology 27(11):1089-1096. https://doi.org/10. 1007/s00170-004-2287-0

34. Dairanieh IS, Haufe A, Wolf HJ, Mennig G (1996) Computer simulation of weld lines in injection molded poly(methyl methacrylate): Polymer Engineering \& Science. Polymer Engineering \&, Science 36(15):2050-2057. https://doi.org/10.1002/pen.10600

35. Miled H, Silva L, Coupez T, Agassant JF (2012) Injection molding of fibre reinforced thermoplastics: Integration of fibre orientation and mechanical properties computations: International polymer processing. Int Polym Process 27(5):547-556. https://doi.org/10.3139/217.2602

36. Park H, Cha B, Cho S, Kim D, Choi JH, Pyo BG, Rhee B (2016) A study on the estimation of plastic deformation of metal insert parts in multi-cavity injection molding by injection-structural coupled analysis. The International Journal of Advanced Manufacturing Technology 83(9):2057-2069. https://doi.org/10.1007/s00170-015-7694-x

37. Li X, Gong N, Gao Z, Yang C (2017) Fiber orientation in melt confluent process for reinforced injection molded part. The International Journal of Advanced Manufacturing Technology 90(5):14571463. https://doi.org/10.1007/s00170-016-9333-6

38. Dray D, Gilormini P, Régnier G (2007) Comparison of several closure approximations for evaluating the thermoelastic properties of an injection molded short-fiber composite. Compos Sci Technol 67(7):1601-1610. https://doi.org/10. 1016/j.compscitech.2006.07.008

39. Kammoun S, Doghri I, Adam L, Robert G, Delannay L (2011) First pseudo-grain failure model for inelastic composites with misaligned short fibers. Compos A: Appl Sci Manuf 42(12):18921902. https://doi.org/10.1016/j.compositesa.2011.08.013

40. Masseria F, Berger A, Kaiser B (2015) Virtual composite manufacturing simulation chain. In: 20th symposium on composites, trans tech publications, materials science forum, vol 825, pp 671-676. https://doi.org/10.4028/www.scientific.net/MSF.825-826.671

41. Hürkamp A, Gebken T, Müller A, Dröder K (2018) Multiscale simulation of short fiber reinforced plastics for hybrid composites. In: 18th European conference on composite materials (ECCM18)

42. Amann C, Kreissl S, Grass H, Meinhardt J, Merklein M (2016) Industrial distortion simulation of fibre reinforced plastics a study on finite element discretisation. Advanced Materials Research 1140:272-279. https://doi.org/10.4028/www.scientific. net/AMR.1140.272

43. Amann C, Kreissl S, Grass H, Meinhardt J (2017) A review on process-induced distortions of carbon fiber reinforced thermosets for large-scale production. Prod Eng 11(6):665-675. https://doi.org/10.1007/s11740-017-0772-1 
44. Chinesta F, Cueto E, Abisset-Chavanne E, Duval JL, Khaldi FE (2018) Virtual, digital and hybrid twins: a new paradigm in data-based engineering and engineered data. Archives of Computational Methods in Engineering. https://doi.org/10.1007/s11831018-9301-4

45. Kambhatla N, Leen TK (1997) Dimension reduction by local principal component analysis. Neural Comput 9(7):1493-1516. https://doi.org/10.1162/neco.1997.9.7.1493

46. Berkooz G, Holmes P, Lumley JL (1993) The proper orthogonal decomposition in the analysis of turbulent flows. Annual Review of Fluid Mechanics 25(1):539-575

47. Radermacher A, Reese S (2013) A comparison of projectionbased model reduction concepts in the context of nonlinear biomechanics. Arch Appl Mech 83(8):1193-1213. https://doi.org/10. 1007/s00419-013-0742-9

48. Radermacher A, Reese S, Hadoush AMH (2013) Selective proper orthogonal decomposition model reduction for forming simulations. PAMM 13(1):115-116. https://doi.org/10.1002/ pamm.201310053

49. Hürkamp A, Kaliske M (2015) A model reduction approach for hyperelastic materials based on Proper Orthogonal Decomposition. PAMM 15(1):203-204. https://doi.org/10.1002/pamm. 201510092

50. Ammar A, Mokdad B, Chinesta F, Keunings R (2006) A new family of solvers for some classes of multidimensional partial differential equations encountered in kinetic theory modeling of complex fluids. J Non-Newtonian Fluid Mech 139(3):153-176. https://doi.org/10.1016/j.jnnfm.2006.07.007

51. Ammar A, Mokdad B, Chinesta F, Keunings R (2007) A new family of solvers for some classes of multidimensional partial differential equations encountered in kinetic theory modelling of complex fluids: Part II: Transient simulation using spacetime separated representations. J Non-Newtonian Fluid Mech 144(2):98-121. https://doi.org/10.1016/j.jnnfm.2007.03.009

52. Chinesta F, Ladeveze P, Cueto E (2011) A short review on model order reduction based on proper generalized decomposition. Archives of Computational Methods in Engineering 18(4):395. https://doi.org/10.1007/s11831-011-9064-7

53. Quaranta G, Abisset-Chavanne E, Chinesta F, Duval JL (2018) A cyber physical system approach for composite part: From smart manufacturing to predictive maintenance. AIP Conference Proceedings 1960(1):020025. https://doi.org/10.1063/1.5034826

54. Han ZH, Zhang KS (2012) Surrogate-based optimization. In: Roeva O (ed) Real-world applications of genetic algorithms, InTech

55. Elanayar VTSS, Shin YC (1994) Radial basis function neural network for approximation and estimation of nonlinear stochastic dynamic systems. IEEE Transactions on Neural Networks 5(4):594-603. https://doi.org/10.1109/72.298229

56. Park J, Sandberg IW (1991) Universal approximation using Radial-Basis-Function networks. Neural Comput 3(2):246-257. https://doi.org/10.1162/neco.1991.3.2.246

57. Smola AJ, Schölkopf B (2004) A tutorial on support vector regression. Statistics and Computing 14(3):199-222. https://doi.org/10.1023/B:STCO.0000035301.49549.88

58. Liang L, Liu M, Martin C, Sun W (2018) A deep learning approach to estimate stress distribution: a fast and accurate surrogate of finite-element analysis. Journal of the Royal Society, Interface 15(138). https://doi.org/10.1098/rsif.2017.0844

59. Negahban A, Smith JS (2014) Simulation for manufacturing system design and operation: literature review and analysis. J Manuf Syst 33(2):241-261. https://doi.org/10.1016/j.jmsy.2013.12.007

60. Garwood TL, Hughes BR, Oates MR, O'Connor D, Hughes $R$ (2018) A review of energy simulation tools for the manufacturing sector. Renew Sust Energ Rev 81:895-911. https://doi.org/10.1016/j.rser.2017.08.063
61. Seow Y, Rahimifard S (2011) A framework for modelling energy consumption within manufacturing systems. CIRP J Manuf Sci Technol 4(3):258-264. https://doi.org/10.1016/j.cirpj.2011. 03.007

62. Buth L, Broderius N, Herrmann C, Thiede S (2017) Introducing agent-based simulation of manufacturing systems to industrial discrete-event simulation tools. In: 2017 IEEE 15th international conference, pp 1141-1146. https://doi.org/10.1109/INDIN.2017. 8104934

63. Abele E, Braun S, Schraml P (2015) Holistic simulation environment for energy consumption prediction of machine tools. Procedia CIRP 29:251-256. https://doi.org/10.1016/j.procir.2015.02. 059

64. Herrmann C, Thiede S, Kara S, Hesselbach J (2011) Energy oriented simulation of manufacturing systems - concept and application. CIRP Ann 60(1):45-48. https://doi.org/10.1016/j.cirp.2011. 03.127

65. Thiede S (2012) Energy efficiency in manufacturing systems springer berlin heidelberg. Berlin, Heidelberg. https://doi.org/10. 1007/978-3-642-25914-2

66. Schönemann M, Schmidt C, Herrmann C, Thiede S (2016) Multilevel modeling and simulation of manufacturing systems for lightweight automotive components. Procedia CIRP 41:10491054. https://doi.org/10.1016/j.procir.2015.12.063

67. Louhichi B, Abenhaim GN, Tahan AS (2015) CAD/CAE integration: updating the CAD model after a FEM analysis. The International Journal of Advanced Manufacturing Technology 76(1):391-400. https://doi.org/10.1007/s00170-014-6248-y

68. Posselt G, Fischer J, Heinemann T, Thiede S, Alvandi S, Weinert N, Kara S, Herrmann C (2014) Extending energy value stream models by the TBS dimension - applied on a multi product process chain in the railway industry. Procedia CIRP 15:80-85. https://doi.org/10.1016/j.procir.2014.06.067

69. Hufenbach WA, Werner J, Kiele J (2013) Elektromobilität in Ultraleichtbauweise. ATZextra 18(2):42-46. https://doi.org/10. 1365/s35778-013-0019-5

70. Modler N, Adam F, Maaß J, Kellner P, Knothe P, Geuther M, Irmler C (2015) Intrinsic lightweight steel-composite hybrids for structural Components. Mater Sci Forum 825-826:401-408. https://doi.org/10.4028/www.scientific.net/MSF.825-826.401

71. Hopmann C, Klein J, Schönfuß BI, Reisgen U, Schönberger J, Schiebahn A (2017) Analysis and specification of the crash behaviour of plastics/metal-hybrid composites by experimental and numerical methods. Production Engineering 11(2):183-193. https://doi.org/10.1007/s11740-017-0727-6

72. Haider DR, Krahl M, Gude M, Hengstmann R, Titze S, Haupt M (2017) Continuous data measurement and analysis in automated manufacturing processes for hybrid lightweight structures. In: SAMPE conference, pp 14-16

73. Dröder K, Brand M, Kühn M (2017) Numerical and experimental analyses on the influence of array patterns in hybrid metal-FRP materials interlocked by mechanical undercuts. Procedia CIRP 62:51-55. https://doi.org/10.1016/j.procir.2016.06.121

74. Koch SF, Barfuss D, Bobbert M, Groß L, Grützner R, Riemer M, Stefaniak D, Wang Z (2016) Intrinsic hybrid composites for lightweight structures: new process chain approaches. Advanced Materials Research 1140:239-246. https://doi.org/10.4028/www.scientific.net/AMR.1140.239

75. Wollmann J, Haider DR, Krahl M, Langkamp A, Gude M (2019) Linked a priori and a posteriori models of composite manufacturing process chain. In: Rusiński E, Pietrusiak D (eds) Proceedings of the 14th international scientific conference: computer aided engineering. Springer International Publishing, Cham, pp 823-828 
76. Federal Ministry of Education and Research - BMBF (2018) Open Hybrid LabFactory Research Campus - The LightweightCampus. https://www.forschungscampus.bmbf.de/research_campuses/ open-hybrid-lab-factory

77. Droste A, Naughton P, Bowser B, Röttger J, Burr S, Imam O, Zeitler M, Heuft T, Cawley A (2003) Bonded metal-plastic composite structures. In: SPE automotive composite conference troy, Michigan, USA

78. Bader B, Berlin W, Demes M (2019) Improvement of lightweight design quality through interdisciplinary cooperation. Lightweight Design worldwide 12(3):38-43. https://doi.org/10.1007/s41777019-0024-5

79. Ceretti E, Taupin E, Altan T (1997) Simulation of metal flow and fracture applications in orthogonal cutting, blanking, and cold extrusion. CIRP Ann 46(1):187-190. https://doi.org/10.1016/ S0007-8506(07)60805-1

80. Schulz W, Nießen M, Eppelt U, Kowalick K (2009) Simulation of laser cutting. In: Dowden J (ed) The theory of laser materials processing: heat and mass transfer in modern technology. Springer, Netherlands, pp 21-69. https://doi.org/10.1007/978-1-4020-9340-1

81. Feng Y, Jianming W, Feihong L (2012) Numerical simulation of single particle acceleration process by SPH coupled FEM for abrasive waterjet cutting. The International Journal of Advanced Manufacturing Technology 59(1):193-200. https://doi.org/10.1007/s00170-011-3495-Z

82. Cha WG, Hammer T, Gutknecht F, Golle R, Tekkaya AE, Volk W (2017) Adaptive wear model for shear-cutting simulation with open cutting line. Wear 386-387:17-28. https://doi.org/10.1016/j. wear.2017.05.019

83. Werber A, Liewald M, Nester W, Grünbaum M, Wiegand K, Simon J, Timm J, Hotz W (2013) Assessment of forming limit stress curves as failure criterion for non-proportional forming processes. Prod Eng 7(2):213-221. https://doi.org/10.1007/s11740013-0446-6

84. Livermore Software Technology Corporation (2018) LS-DYNA

85. Behrens BA, Chugreev A, Wester H (2019) Experimental and numerical characterization method for forming behavior of thermoplastics reinforced with woven fabrics. Procedia Manufacturing 29:443-449. https://doi.org/10.1016/j.promfg.2019.02.160

86. Autodesk (2017) Moldflow insight

87. Williams ML, Landel RF, Ferry JD (1955) The temperature dependence of relaxation mechanisms in amorphous polymers and other glass-forming liquids. J Am Chem Soc 77(14):3701-3707. https://doi.org/10.1021/ja01619a008

88. Folgar F, Tucker CL (1984) Orientation behavior of fibers in concentrated suspensions. J Reinf Plast Compos 3(2):98-119. https://doi.org/10.1177/073168448400300201

89. Advani SG, Tucker CL (1987) The use of tensors to describe and predict fiber orientation in short fiber composites. Journal of Rheology 31(8):751-784. https://doi.org/10.1122/1.549945

90. Bay RS, Tucker CL (1992) Fiber orientation in simple injection moldings. Part I: Theory and numerical methods: Polymer Composites. Polym Compos 13(4):317-331. https://doi.org/10.1002/pc.750130409

91. Wang J, O'Gara JF, Tucker CL (2008) An objective model for slow orientation kinetics in concentrated fiber suspensions: theory and rheological evidence. J Rheol 52(5):1179-1200. https://doi.org/10.1122/1.2946437

Publisher's note Springer Nature remains neutral with regard to jurisdictional claims in published maps and institutional affiliations. 